\title{
Segment tip geometry of sheet intrusions, II: Field observations of tip geometries and a model for evolving emplacement mechanisms
}

\author{
Tara L. Stephens ${ }^{\star \alpha, \beta}$, Richard J. Walker ${ }^{\alpha}$, David Healy $\beta$, Alodie Bubeck $\gamma$ \\ ${ }^{\alpha}$ School of Geography, Geology and the Environment, University of Leicester, Leicester, LE1 7RH, UK. \\ $\beta$ School of Geosciences, King's College, University of Aberdeen, Aberdeen, AB24 3UE, UK.

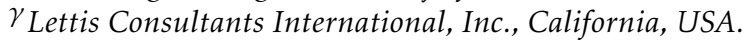

\begin{abstract}
Igneous sheet intrusions are segmented across several orders of magnitude, with segment tip geometry commonly considered indicative of the propagation mechanism (brittle or non-brittle). Proposed propagation mechanisms are inferred to represent host rock mechanical properties during initial magma emplacement; typically, these models do not account for segment sets that show a range of tip geometries within the same lithology. We present a detailed structural characterisation of basaltic sill segments and their associated host rock deformation from the Little Minch Sill Complex, Isle of Skye, UK. Each separate host lithology shows multiple tip geometries and styles of host rock deformation, from elastic-brittle fracture to viscous indentation and fluidisation. We attribute this range of host rock deformations to evolving conditions that occured at the tips both during sheet growth and arrest.
\end{abstract}

\section{NON-TECHNICAL SUMMARY}

\begin{abstract}
Magma commonly moves through Earth's crust within a plumbing system of interlinked sheet-like fractures. These sheets start as short segments, which grow and link through time. Underground growth of magma plumbing systems cannot be observed directly, so much of our understanding of sheet growth comes from excavated and longsince cooled remnants of extinct volcanoes. The way that sheets grew is typically inferred from their shape, and the way in which the surrounding rocks were broken (deformation) to allow magma to flow through. Current models invoke growth by a single style of rock deformation. Here, we analyse exposed magmatic segments which show numerous sheet shapes and styles of rock deformation. We attribute these features to local changes in the magma and rock properties during and after sheet growth. Our results have direct implications to our understanding of the mechanics of active magmatic plumbing systems, as the signals of magma propagation may change over time.
\end{abstract}

Keywords: Sill segment geometry; Sill emplacement mechanisms; Structural characterisation; This article is a companion to Walker et al. [2021] DoI: 10.30909/vol.04.02.189201.

\section{INTRODUCTION}

Magmatic sheet intrusions, such as sills and dykes, play a fundamental role in magma transport through the Earth's crust. Field observations, seismic surveys, and analogue models have revealed that sheet intrusions are commonly segmented across several orders of magnitude in scale, from centimetres to kilometres [e.g. Pollard et al. 1975; Hansen and Cartwright 2006; Wyrick et al. 2015]. Segment geometry is typically linked to a mechanism of propagation, by association with host rock deformation. However, the process of intrusion, and therefore the causal link to geometry, cannot be directly observed in nature. Instead, remote sensing methods such as monitoring seismicity and ground deformation are used to infer mechanisms of host rock deformation in the shallow crust [e.g. Biggs et al. 2009;

${ }^{*}$ Corresponding author: tara.stephens@abdn.ac.uk
Ágústsdóttir et al. 2016; Magee et al. 2018]. The conceptual models used to inform interpretations of seismicity and ground deformations are derived from field observations of exposed intrusions, hence studying preserved magmatic networks is critical for developing our understanding of the mechanism(s) of magma propagation, and the likely signatures of emplacement.

Traditionally, magmatic segments have been treated as Mode I hydrofractures, and their propagation simplified within a Linear Elastic Fracture Mechanics (LEFM) framework: segments are idealised as sheets with tapered (wedge-shaped) tips [e.g. Pollard 1973; Rubin 1993]. Many field studies have identified intrusive segments that are not tapered: finger-like forms with rounded (lobate) or blunt tip geometries [e.g. Pollard et al. 1975; Delaney and Pollard 1981; Hutton 2009; Schofield et al. 2010; Kavanagh and Sparks 2011; Walker et al. 2017; Healy et al. 2018; Galland et al. 2019; Kjøll et al. 2019]. Lobate or blunt tips cannot 
form via linear elasticity, which has led to the development of various non-brittle propagation models, including viscous indentation and bulldozing [e.g. Spacapan et al. 2017], host rock fluidisation [e.g. Schofield et al. 2010], and localised shear-failure and/or ductile flow [e.g. Pollard 1973; Haug et al. 2017]. These mechanisms are considered to be governed by the host rock lithology and mechanical properties at the time of initial magma emplacement [e.g. Schofield et al. 2010; 2012; Spacapan et al. 2017; Haug et al. 2018].

An issue that is generally omitted in intrusion growth models is that magma and host rock properties can change during the lifetime of an intrusive event [Poppe et al. 2020]. Modifications to the conditions of emplacement during magma propagation, such as increasing magma viscosity during cooling, have been shown to result in modifications to the intrusion geometry and the associated style of host rock deformation for cryptodomes and laccoliths [e.g. Currier and Marsh 2015; Mattsson et al. 2018; Burchardt et al. 2019]. Such modifications are also likely to occur in segmented sheet intrusions, and since late-stage processes have the potential to overprint early structures, segment geometries as observed in the field, may be representative only of the final stage of emplacement, rather than the emplacement process as a whole [Walker et al. 2021].

Here, we use detailed field observations of intrusive segments to develop a new conceptual dynamic model that accounts for evolving intrusive segment geometries in a dominantly brittle host rock by considering modifications to the conditions of emplacement. We present examples from the Little Minch Sill Complex, Isle of Skye, UK where intrusive segments display different tip geometries in the same host rock to highlight that intrusive segment geometry and the style of host rock deformation may vary with changes to the conditions of emplacement. Segments observed in the field provide a snapshot of the final conditions of the arresting intrusion process.

\section{BACKGROUND}

2.1 Mechanisms of segment propagation and resulting geometry

Propagation mechanisms are currently split into two main groups: elastic-brittle and non-brittle. This section summarises the key models of intrusive segment propagation and their associated styles of host rock deformation. Several factors influence the propagation mechanism, including host rock properties such as lithology [e.g. Schofield et al. 2012], cohesion [Schmiedel et al. 2017], and elastic moduli (such as Young's modulus, E; Poisson's ratio, $v$; and shear modulus, $\mu$ [e.g. Haug et al. 2017; Haug et al. 2018]). Other factors include strain rate [Pollard 1973], magma viscosity [Chanceaux and Menand 2016; Mattsson et al.

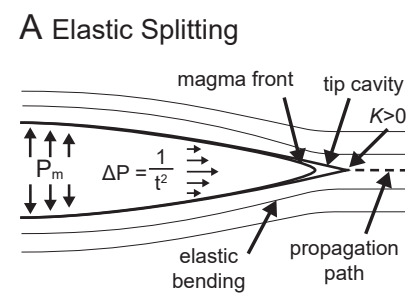

B Barenblatt-cohesive zone

C Fluidisation

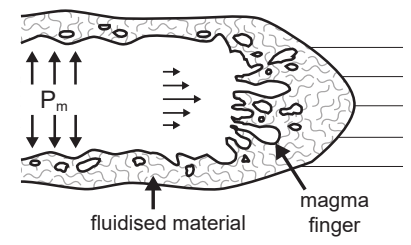

E Brittle Faulting

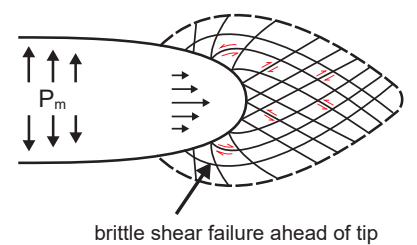

F Ductile Faulting \& Flow

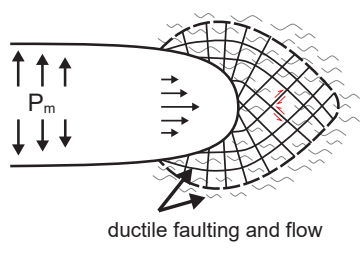

Figure 1: Propagation mechanisms for intrusion emplacement, and the associated host rock deformation and ideal tip geometries. $P_{m}$, magma pressure; $\Delta P$, driving pressure; $t$, intrusion thickness. $[\mathrm{A}]-[\mathrm{B}]$ Linear elastic fracture mechanics models, $(K$, stress intensity factor): [A] Elastic-splitting model [Pollard 1973; Rubin 1993]; [B] Barenblatt-cohesive zone model; cohesive stress at the fracture tip acts against dilation [Rubin 1993]. [C]-[D] Inelastic propagation models: [C] thermal fluidisation, results in a loss of primary host rock structures (i.e. bedding/ lamination) [e.g. Schofield et al. 2012]; [D] viscous-indenter; shortening occurs within one 'weak' unit, e.g. shale [e.g. Spacapan et al. 2017]. [E] Brittle faulting model [after Pollard 1973]. [F] Ductile faulting and flow model [after Pollard 1973]. Figure redrawn and modified after Spacapan et al. [2017].

2018; Burchardt et al. 2019], magma driving pressure relative to the tectonic stress [Gill and Walker 2020], depth of emplacement [Gill and Walker 2020], and the remote stress state [e.g. Pollard 1973; Pollard et al. 1975; Rubin 1993; Walker and Gill 2020].

\subsection{Elastic-Brittle tip-zone models}

Dyke and sill segment propagation has been considered traditionally as an elastic-brittle deformation (Figure 1A-B). Two models have been proposed: (1) the elastic-splitting model [Figure 1A; Pollard 1973], and (2) the Barenblatt-cohesive zone model [Figure 1B; Rubin 1993].

The Elastic Splitting Model conforms to linear elastic fracture mechanics (LEFM), where fractures have slit- 
like geometries, with sharp wedge-shaped (tapered) tips (Figure 1; e.g. Pollard [1973]). The elastic splitting model has been linked to magma emplacement in brittle host rock at low confining stress and temperature, or emplacement at high strain rates under high confining stress [Pollard 1973]. In LEFM, hydrofracture propagation occurs when the stress intensity factor at the crack tip $K$ equals or exceeds a critical value: the material fracture toughness $\left(K_{c}\right)$ [Rubin 1995]. For a non-propagating segment with a uniform internal driving pressure in an infinite medium, the stress intensity at the crack tip is related to the crack length via [Rubin 1995]:

$$
K=\Delta P \sqrt{l}
$$

where the driving pressure $(\Delta P)$ is the total fluid pressure in the fracture $\left(P_{f}\right)$ minus the normal stress $\left(\sigma_{n}\right)$ acting on the fracture plane $\left(\Delta P=P_{f}-\sigma_{n}\right)$. The stress distribution $\left(\sigma_{\mathrm{ij}}\right)$ at the crack tip can be calculated in polar coordinates $(r, \theta)$ as [Lawn 1975]:

$$
\sigma_{\mathrm{ij}}(r, \theta)=K / \sqrt{2 \pi r} f_{\mathrm{ij}}(\theta)
$$

where the polar origin is at the crack tip, $K$ is the stress intensity factor, $r$ is the tip radius of curvature, and $f_{\mathrm{ij}}(\theta)$ is a function of angular position around the tip and depends on crack geometry and loading mode [Atkinson 1987]. Theoretically the stress at the crack tip should approach infinity as $r \rightarrow 0$ (a tapered tip geometry); however infinite stresses are prevented in nature by the material yield strength, and instead a zone of non-elastic deformation develops ahead of the crack tip (i.e. the process zone). Where LEFM applies, the process zone is small relative to the length of the intrusion [Rubin 1993] and the stress intensity decays with distance from the crack tip. The host rock bends elastically to accommodate the fracture aperture, such that layer thicknesses remains constant above and below the intrusion.

The Barenblatt-Cohesive Zone Model builds upon the elastic splitting model to include a cohesive process zone at the intrusion tip (Figure 1B). Cohesive stresses act to resist dilation and are on the order of the host rock tensile strength, such that the stress intensity $(K)$ at the crack tip is reduced toward zero [Figure 1B Rubin 1993]. During propagation of a bladed magmafilled fracture, the average flow velocity of the magma in the direction of propagation approaches the tip velocity [Rubin 1995]. In this condition, the pressure gradient $\Delta P / d x$ varies approximately as $1 / t^{2}$ (where $d x$ is the along-intrusion dimension, and $t$ is intrusion thickness), hence the magma should lose its pressure within the very narrow tip region, leaving a gap between the viscous magma and the physical fracture tip [Barenblatt 1962]. This zero-pressure cavity may become filled with exsolved volatiles from the magma, or from inflow of host rock pore fluids [e.g. Pollard 1973; Lister 1990; Rubin 1993; 1995; Poppe et al. 2020]. Inflow of pore fluids may cause non-localised inelastic damage in the process zone ahead of the intrusion, which increases the energy required for continued fracture propagation [Rubin 1993; Gudmundsson 2011]. However, the pressure gradient arising from low pressure in the cavity also serves to drive magma flow toward the tip [Gill and Walker 2020]. Importantly in the Barenblatt model, if the magma driving pressure cannot drive further propagation of the fracture plane, it will instead cause inflation and rounding of the magma front, blunting the preserved tip geometry.

\subsection{Non-brittle tip-zone models}

During non-brittle magma propagation, the host rock behaves as a ductile or viscous medium ahead of the propagating tip. Viscosity contrasts influence the style of host rock deformation: when the magma viscosity exceeds that of the host rock, the magma may behave as a viscous indenter, whereas a low viscosity magma intruding into a more viscous host rock may generate a Saffman-Taylor instability, causing the magma front to break down into an array of magma fingers [Saffman and Taylor 1958]. Two key models of nonbrittle magma propagation have been proposed: (1) fluidisation, and (2) bulldozing or viscous indentation.

Fluidisation is typically attributed to local heating of pore-fluids close to the intrusion, which causes the pore-fluid-pressure to exceed the host rock cohesion, causing disaggregation and flow of the host rock [Kokelaar 1982; Schofield et al. 2010; 2012]. Accordingly, fluidised host rock is most commonly associated with intrusions emplaced into saturated, unconsolidated or poorly consolidated sedimentary materials that have low or zero cohesion. Fluidisation is thus typically associated with shallow-level intrusions [Kokelaar 1982; Robertson 1988; Schofield et al. 2010; 2012; 2014]. Intrusions that propagate via fluidisation typically have lobate and/or irregular tip geometries, and are associated with an enveloping zone, or carapace, of fluidised host rock that has lost its internal structure [Figure 1C; Schofield et al. 2010; 2012; 2014].

Bulldozing or viscous indentation models involve host rock buckling, folding, faulting, and/or ductile flow. This deformation results in a thickening of the host rock ahead of a rounded or blunt intrusion tip, of a magnitude similar to the thickness of the intrusion [Figure 1D; e.g. Pollard 1973; Merle and Donnadieu 2000; Spacapan et al. 2017]. Lobate segments with a large width relative to thickness generate large shear and compressive stress concentrations at their tips, which may overcome the shear strength of the adjacent host rock or discontinuities (e.g. bedding planes) to cause bedding plane slip and buckling of strata [Pollard et al. 1975; Rubin 1993]. Pollard [1973] proposed two end-member models to account for wedge-shaped zones of faulted host rock ahead of rounded segment tips: brittle-shear failure and ductile-shear failure, both of which resemble Hencky-relation slip line solutions for 
a pressurised hole in an infinite plate [e.g. Nádai 1950; d'Escatha and Mandel 1974]. Brittle shear failure generates faults oriented $\sim 30^{\circ}$-dependent on the angle of internal friction $(\phi)$ for the rock-from the maximum local compressive stress $\left(\sigma_{1}\right)$ about the intrusion tip (Figure 1E), while ductile-shear failure produces faults oriented $\sim 45^{\circ}$ from the local $\sigma_{1}$ (i.e. in the plane of maximum shear stress, $\tau_{\max }$ ) [Figure 1F; Pollard 1973]. Notably, the segment tip geometry controls the location of shear stress concentrations about the tip [e.g. Obert and Duvall 1967; Walker et al. 2021]. Shear stress will concentrate at the segment tip maximum curvature; in the case of a circular tip this is a single concentration distributed around the tip [e.g. Pollard 1973; Souche et al. 2019], but in the case of a superelliptical or rectangular tip geometry [e.g. Merle and Donnadieu 2000; Walker et al. 2021], this is not the case.

Field examples indicate that a range of segment tip geometries (from tapered through to squared) can occur in a single study area (Figure 2; see also Walker et al. [2021], their Figures 1-2). Many studies consider the segment tip geometry as observed in the field to be representative of the growing intrusion. Pollard [1973] suggested that ductile-shear failure, brittle-shear failure, and elastic splitting models form a spectrum of propagation mechanisms that depend on the confining stress, temperature, pore fluid pressure, and strain rate. Changing one or more of these parameters could therefore result in multiple tip geometries on a single intrusion [for examples see Kjøll et al. 2019; Poppe et al. 2020]. Segment tip geometries as observed in the field are therefore most likely to represent the processes occurring during the final stage of emplacement (i.e. the 'death' of the segment; Walker et al. [2021]). Hence, intrusive segment geometry-and propagation mechanism-may evolve over the lifespan of a segment. To investigate this theory, we present a detailed characterisation of segmented sills in the Little Minch Sill Complex, Isle of Skye.

\subsection{Geometrical classification of segmented sheet in- trusions}

We define individual segments by the length of their semi-axes, with the major, intermediate, and minor semi-axes $a \geqslant b \gg c$; total segment thickness $t=2 c$, width $w=2 b$, and length $l=2 a$ (Figure 3A). Magmatic segments grow in three-dimensions while propagating away from the parent sheet, but due to exposure limitations segments are often observed in the field in twodimensional sections. In three dimensions, the segment has a frontal tip which represents the bulk propagation direction, predominantly parallel to the segment length (ideally viewed in sections oriented parallel to segment length); and lateral tips which represents the local lateral segment growth (ideally viewed in sections parallel to segment width and perpendicular to the main segment propagation direction) (Figure 3A). Defining which tip is observed therefore requires knowledge or an interpretation of the bulk and local propagation direction, which is generally considered to occur as a lengthening where $a \gg b>c$ followed by segment linkage and widening such that $b \rightarrow a$ [e.g. Magee et al. 2016]. Frontal tips are inferred where only one tip is exposed and no adjacent segments are observed, whereas arrays of adjacent segments indicate observations are of lateral tips.

The spatial relationship between adjacent segments is described by their offset and separation [Delaney and Pollard 1981]. Offset is measured here as the caxis-parallel distance between the centreline of adjacent segments; separation is the width-parallel distance between the tips of adjacent segments, which may display an overlapping or underlapping relationship (Figure 3B). Following Walker et al. [2017] and Healy et al. [2018], we refer to the region between two adjacent segments as the relay zone (termed 'bridge' by Delaney and Pollard [1981]), and more specifically as either an overlap zone or underlap zone determined by the segment arrangement. Where segments have linked across the relay zone, we use the term breached relay (c.f. 'broken bridge': Schofield et al. [2010]).

\section{Geological Background}

Our data set is derived from a small $\left(\sim 1.1 \mathrm{~km}^{2}\right)$ outcrop of segmented sills at Neist Point, Isle of Skye, UK (Figure 4A-B), which is situated inboard of the eastern North Atlantic volcanic passive margin. The studied sills form part of the Little Minch Sill Complex (LMSC), a $\sim 4000 \mathrm{~km}^{2}$ sill network emplaced into the Minch Basin between 61-54 Ma, associated with Palaeocene magmatic activity during early rifting phases of the North Atlantic [Gibb and Gibson 1989; Baer 1991; Saunders et al. 1997; Chambers and Pringle 2001; Fowler et al. 2004]. Offshore, the LMSC is confined to the Mesozoic sedimentary infill of the Minch Basin, which forms part of a NE-SW striking Mesozoic half-graben system [Roberts and Holdsworth 1999; Schofield et al. 2016]. No sills are exposed in the footwall of the Minch Fault, on the isles of Lewis and Harris. Onshore Skye, the sills are predominantly exposed along the northern and north-eastern coastline [Gibb and Gibson 1989]. Sill geometries along the NE coast of Skye were used by Schofield et al. [2016] to infer that the LMSC propagated eastwards and was fed by a dyke that exploited the basin-bounding Minch fault at depth.

\section{Results}

\subsection{Field Observations}

In the Neist Point study area three thick sills $(>10 \mathrm{~m}$ thick) are exposed and can be traced in section for more 

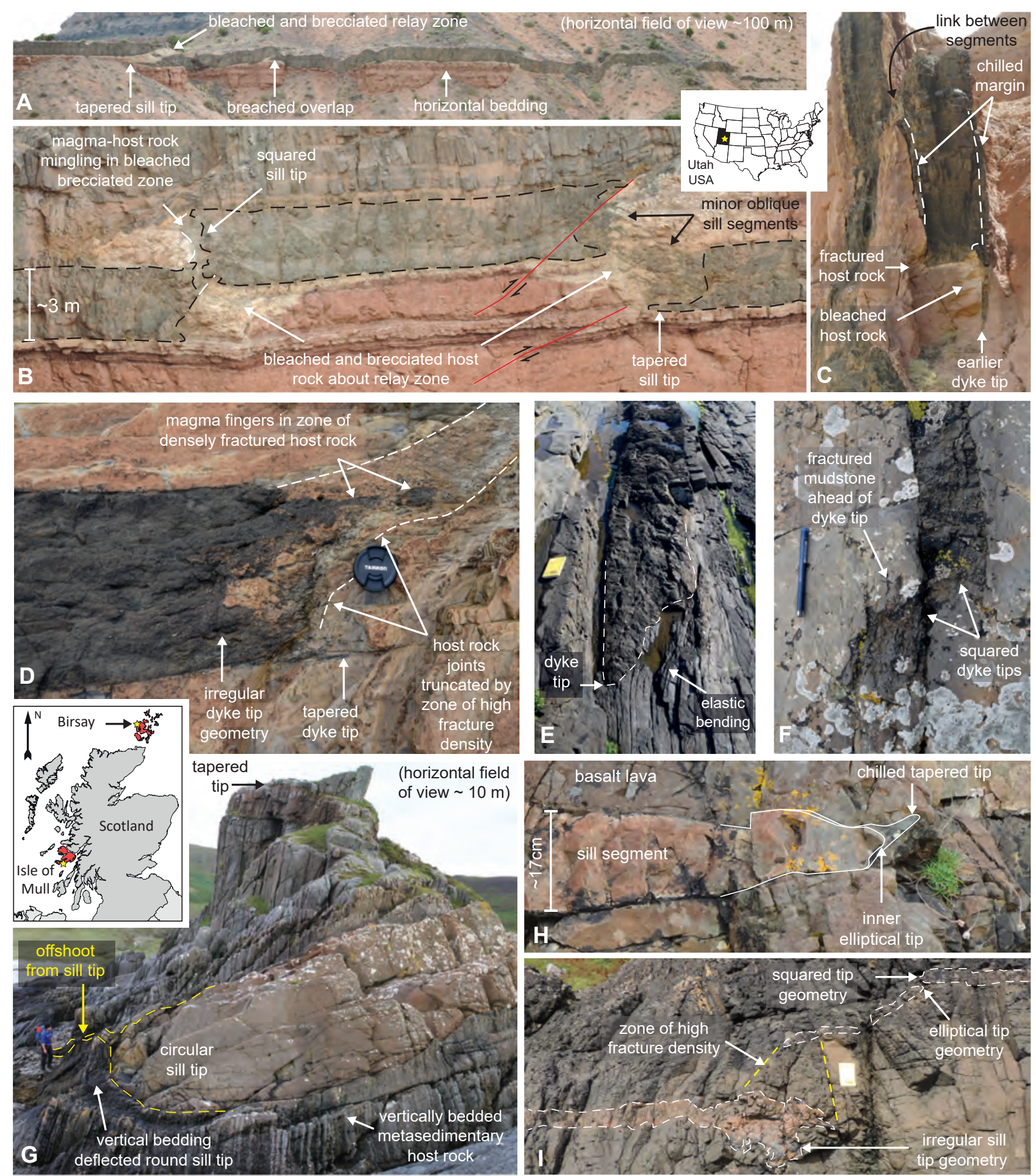

Figure 2: Field examples of tapered to squared sheet intrusion tip geometries. $[A]-[C]$ Basaltic intrusions in horizontal interbedded sandstone-shale sequences, San Rafael Subvolcanic Field, Utah, USA: [A] sill segments with tapered tips; [B] sill segments with squared and tapered tips; [C] dyke segment with tapered and squared tip. [D][F] Basaltic dykes in siltstone and mudstone, Birsay, Orkney, UK: [D] dyke in siltstone with irregular tip geometry, magma fingers intrude the highly fractured zone ahead the dyke tip, lens cap for scale. [E] Dyke in mudstone, joint traces curve around, and are truncated by, the asymmetrical tip, notebook for scale. [F] Underlapping dyke segments in mudstone, locally fractured host rock ahead of squared tips, pen for scale. [G]-[I] Basaltic sill segments, Isle of Mull, UK. [G] Sill segments with circular and tapered tips in vertically bedded metasedimentary host rock. [H] Sill segment with tapered tip in basaltic lava. [I] Sill segment with irregular tip geometry associated with a zone of densely fractured basaltic lava. (Field locations, additional examples, and unannotated photos are available in Supplementary File 1). 

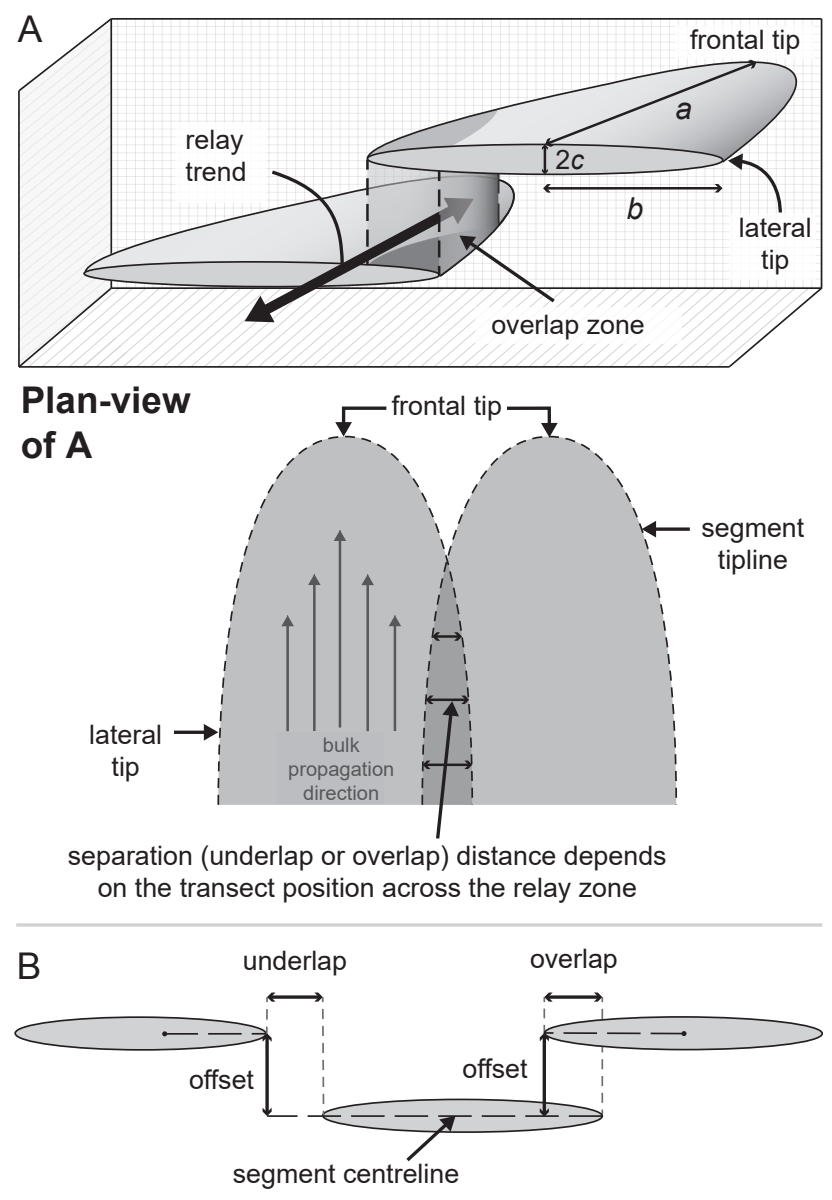

Figure 3: Terminology used here to describe intrusive segments. [A] schematic three-dimensional diagram and plan view below to illustrate segment geometry: thickness $(t=2 c)$, width $(w=2 b)$, length $(l=2 a)$, frontal and lateral tips, and relay zone trend. [B] Terminology describing segment arrangement: separation (underlap or overlap) and offset.

than one kilometre (Figure 4A-B). Those sills dip at a low angle toward the ESE, between $5^{\circ}$ and $7^{\circ}$ (Figure $4 \mathrm{C}$ ), and are mildly discordant to bedding, which has an average dip of $4^{\circ}$ ESE (Figure 4D). These thick sills are spatially associated with interconnected and cross-cutting networks of thin sills ( $\leqslant 2 \mathrm{~m}$ thick) (e.g. Figure 5). Our study focusses predominantly on the network of thin sills shown in Figure 5. Here, the sills intrude the Jurassic Lealt Shale Formation, which consists of subhorizontal and interbedded limestones, sandstones, siltstones, and mudstones. The sills also intrude into the base of the Skye Main Lava Series, however due to their inaccessibility we focus only on segments in the sedimentary strata.

The thin sills are exposed in a NE-SW oriented $\sim 20 \mathrm{~m}$ high cliff section formed of 3 units: a lower sandstone unit interbedded with thin ( $\mathrm{cm}$ to tens-of-cm thick) mudstone beds; this is overlain by a mudstone unit, and an upper sandstone unit (Figure 5A). At the level of ex- posure, the sills occupy $~ 50 \%$ of the total rock volume [Angkasa et al. 2017]. The majority of sills in the study area intrude the lower sandstone, continuous sheets also transgress through the sedimentary sequence as a series of linked offset segments (e.g. segments X-Y-Z on Figure 5A). Non-linked offset and collinear segment arrays are also identified in the sandstone, mudstone, and limestone units, and are the focus here.

Individual segments are parallel to bedding for short distances. In total, we identified 39 segments; $46 \%$ of the identified segments are hosted in mudstone, $33 \%$ in sandstone, and $10 \%$ in limestone; the remaining $10 \%$ are thick segments $(>2 \mathrm{~m})$ with tips that transect multiple beds (Data provided in Supplementary File 2).

Segment pairs display overlapping and underlapping relationships, with offset (en échelon); and collinear arrangements. Stepping directions between adjacent offset segments are inconsistent across the study area. Breached relays between offset segments are predominantly formed of single tip-to-plane links, noted by an abandoned tip (c.f. 'horn': Nicholson and Pollard [1985]) associated with one segment (Figure 5B-C). Breached relays also display near-vertical offset of host rock units across the linkage (Figure 5A-C). Approximately collinear segments, on the other hand, are consistently joined by tip-to-tip links. Relay zones between adjacent segments trend NW-SE and NE-SW across the study area (Figure 5D); prolate amygdales observed at the upper contact of the lower sill in the key study area (Figure 5A) have long-axes trending NW-SE (Figure $5 \mathrm{E}-\mathrm{F})$, suggesting that in this location, the primary magma flow direction was oriented NW-SE, comparable to the relay trends in this location and perpendicular to the cliff section. The studied NE-SW oriented outcrop therefore provides an ideal flow-perpendicular cross-section and an excellent opportunity to characterise segment tip geometry as well as the style and distribution of associated host rock deformation between adjacent segments and ahead of lateral segment tips.

\subsection{Segment Geometry}

We characterise the two-dimensional (2D) crosssectional form of individual segments by measuring their thickness $(t)$, width $(w)$, and radius of curvature of the overall (macro-form: see Figure 6A) tip geometry (henceforth $\rho_{\text {tip }}$ ) from scaled photographs. Photographs were taken oriented parallel to segment tip lines, and of segments exposed on flat cross-sectional surfaces to limit any distortions. Radius of curvature was determined by fitting a best-fit circle to the segment tip using digital images and extracting the radius of that circle, similar to the method employed by Wadell [1935] to measure the roundness of quartz grains. Pollard et al. [1975] describe $\rho_{\text {tip }}$ for elliptical $\left(\rho_{\text {tip }}=t^{2} / 2 w\right)$ and oval $\left(\rho_{\text {tip }}=t / 2\right)$ segment geometries (Figure 6A). In the case of a squared or squared ellipse (i.e. superellipses, or Lamé curves: Lamé [1818]), the 


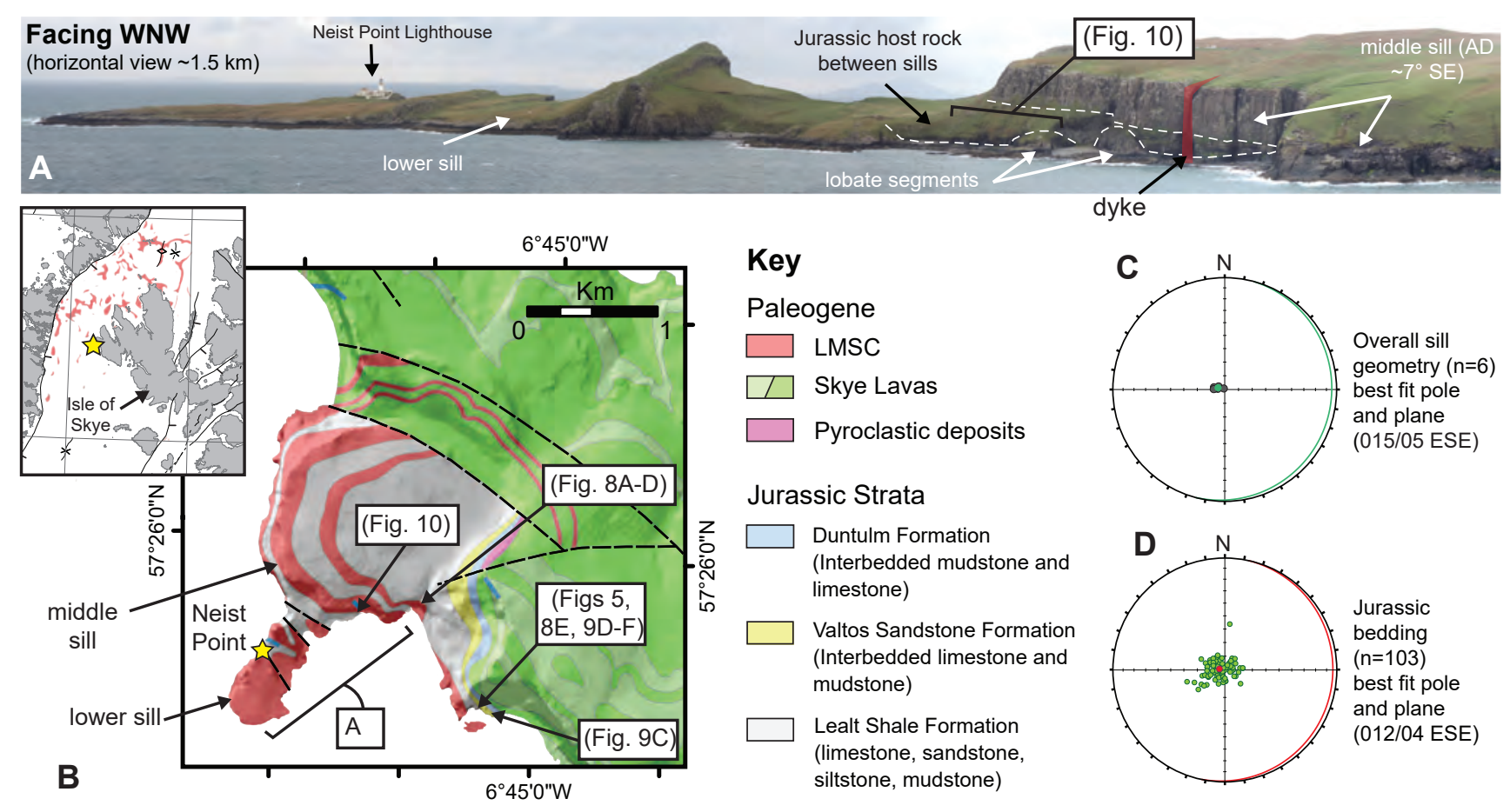

Figure 4: Location of Little Minch Sill Complex study area at Neist Point. [A] Overview photograph of Neist Point showing the lower and middle sills ( $A D=$ apparent dip). [B] Location Map for the Neist Point study area and figure locations with bedrock geology shown at 1:50,000 scale [DiGMapGB-50]. The inset map shows the location of Neist Point on the Isle of Skye (yellow star), and the offshore extent of the Little Minch Sill Complex (LMSC) in red (shown at 1:625000 scale [DiGMapGB-625]). [C] Equal-area lower-hemisphere stereonet plotting the three major sills (grey), with average pole and plane (green), given as strike, dip and dip-direction. [D] Equal-area lowerhemisphere stereonet plotting Jurassic bedding as poles to planes (green), with average pole and plane (red) given as strike, dip and dip-direction.

corners of such geometries will exhibit small $\rho$ values $\left(\rho_{\min }\right)$ that may act to concentrate stress [Figure 6A; Greenspan 1944; Walker et al. 2021]; however for the purpose of our study and to enable comparisons between all segment tip geometries, our measured $\rho_{\text {tip }}$ for squared ellipses approaches infinity as the best-fit circle to a squared tip becomes infinitely large (Figure 6A).

Following Pollard et al. [1975], the results are plotted and compared to curves for idealised oval and elliptical geometries (Figure 6B-C). The thickness to width $(t / w)$ ratio reflects the overall geometry of the segment, where $t / w \rightarrow 0$ represents a thin slit, $t / w \leqslant 0.2$ represents a sheet, and $t / w \rightarrow 1$ represents a magma finger with a near-circular cross-section. The tip geometry is characterised as the $\rho_{\text {tip }}$ to segment width ratio $\left(\rho_{\text {tip }} / w\right)$; where sharp tapered (wedge-shaped) tips would plot at $\rho_{\text {tip }}=0$, tips with a circular form plot on the oval line, squared ellipses plot above the oval line, and perfectly squared tips would plot at $\rho_{\text {tip }}=\infty$ [Pollard et al. 1975].

Of the 39 identified segments, 26 segments could be measured and a total of 43 segment tip geometries were characterised (see Supplementary File 2). Individual segments are denoted in Figure $6 \mathrm{~B}-\mathrm{C}$ by two discrete data points (one measurement per tip) joined by a line. In some cases, only one segment tip could be measured due to limited exposure or tip-to-plane links between adjacent segments, these are shown in Figure $6 \mathrm{~B}-\mathrm{C}$ by a single data point. Most of the measured segments display sheet-like geometries (where $0<t / w<0.2$; Figure $6 \mathrm{~B}$ ), and predominantly plot between the elliptical and oval lines. All overlapping segments have tapered tips and have $\rho_{\text {tip }} / w$ values $\leqslant 0.01$ (Figure 6B), while underlapping segments display a range of tip geometries from tapered to squared ellipses (superelliptical). Figure $6 \mathrm{~B}$ highlights that this range of tip geometries occurs across all host rock lithologies (sandstone, mudstone, and limestone). Figure 6C shows segment geometry and the style of host rock deformation at the tip. Comparing Figure 6B and 6C shows that segments with tapered tips are associated with deflected bedding around the tapered tip and localised fracturing across all host rock lithologies. Most segments with elliptical to squared ellipse tip geometries are associated with a loss of primary host rock structure.

Figure $6 \mathrm{~B}-\mathrm{C}$ also highlights segment asymmetry, denoted by the line-length between the data points. The data point with higher $\rho_{\text {tip }} / w$ is relatively more rounded, while the data point with a lower $\rho_{\text {tip }} / w$ is relatively less rounded: the greater the line-length the greater the segment asymmetry. Through re-plotting 

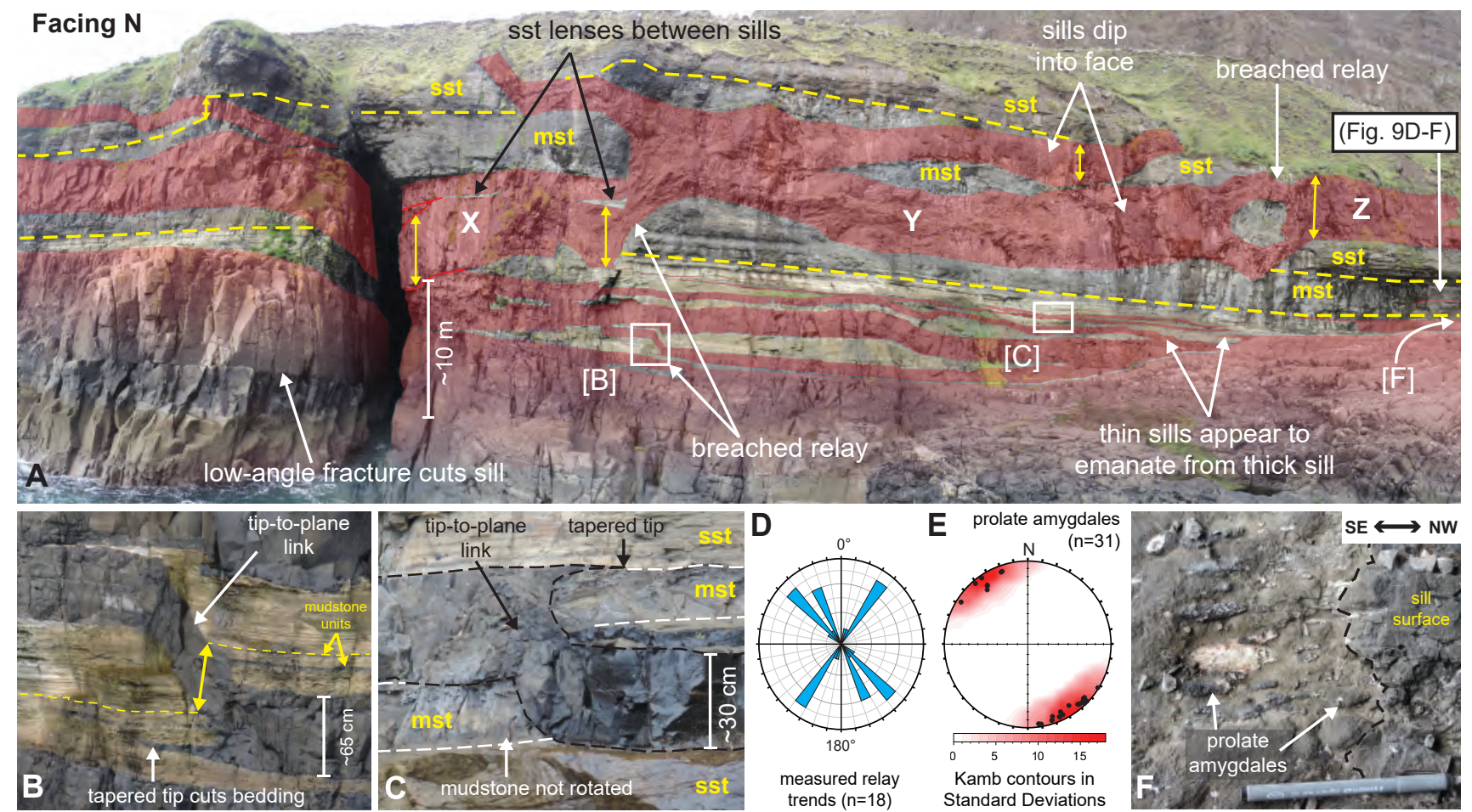

Figure 5: [A] Thin sill network in the Neist Point study area, sills display consistent near-vertical uplift of host rock (yellow arrows). Right-(NE)-stepping linked segments (X-Y-Z) transgress through sandstone (sst) and mudstone (mst) units at the tens-of-metre scale. [B]-[C] examples of linked offset segments in sandstone: [B] tip-to-plane link, left-(SW)-stepping; [C] tip-to-plane link, left-(SW)-stepping; host rock is not rotated within these relays. [D] Rose diagram showing relay trends in the study area, predominant trends are NW-SE and NE-SW; bins are split into $10^{\circ}$ intervals and each bin represents 1 measurement. [E] Colour contoured equal-area lower- hemisphere stereonet of prolate amygdales at upper sill contact, plotted as lineations (measured as rake). [F] Example of prolate amygdales plotted in [E]. (Unannotated photos available in Supplementary File 1, data available in Supplementary File 2).

and colour-coding segments that belong to particular underlapping multi-segment arrays, we find that the segments central to an array are approximately symmetrical about their centre and have oval to squared ellipse tip geometries (Figure 7A-C). Segments nearer the periphery of the array are asymmetrical, with tapered to elliptical distal tips and proximal tips that approach squared ellipse geometries (Figure 7A-C). This is similar to analogue model results of Pollard et al. [1982] of collinear crack development in an elastic medium (Figure 7D). In their model, tip rounding occurs due to adjacent segments reaching a separation distance at which both segments begin to compete for the available mechanical energy; this competition inhibits Mode I fracture propagation, causing the driving stress to be accommodated via segment inflation and tip rounding.

Notably, Figure 7C shows that some segment tips comprise two parts: a light brown chilled glassy outer tip, and a dark finely crystalline inner tip. In most cases the finely crystalline inner tips are more rounded than the chilled glassy outer tips. Segment B of Array 3 comprises two finely crystalline segments enveloped by a chilled glassy margin, likely caused by flow localisation within the segment.

\subsection{Host Rock Deformation}

The thinly bedded and laminated sedimentary sequence in the Neist Point study area has laterally continuous units at the scale of outcrop. This is important for identifying the style(s) of host rock deformation associated with each intrusive segment [Spacapan et al. 2017; Galland et al. 2019].

Overlapping segments have offset (en échelon) arrangements and are consistently accommodated by rotation of bedding across the relay zone (Figure 8A-E), across scales $(\mathrm{cm}-\mathrm{dm})$. To compare scales, we measure the host rock rotation angle $\beta$, the angle between undisturbed bedding and the rotated bedding orientation in the relay zone. Overlap zones show a negative linear regression for $\beta$ and the relay zone aspect ratio (calculated as separation/offset) indicates that larger overlaps cause smaller deflections of host rock layering, as would be expected (Figure 8F). Secondary structures (i.e. those that are only found between adjacent seg- 


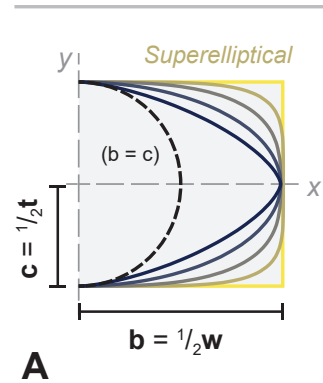

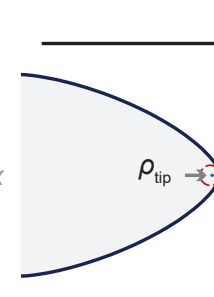

sharp ellipse

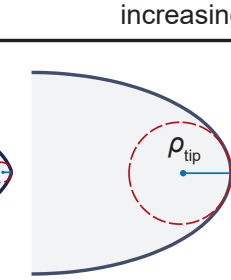

ellipse $\left(\rho_{t i p}=t^{2} / 2 w\right)$
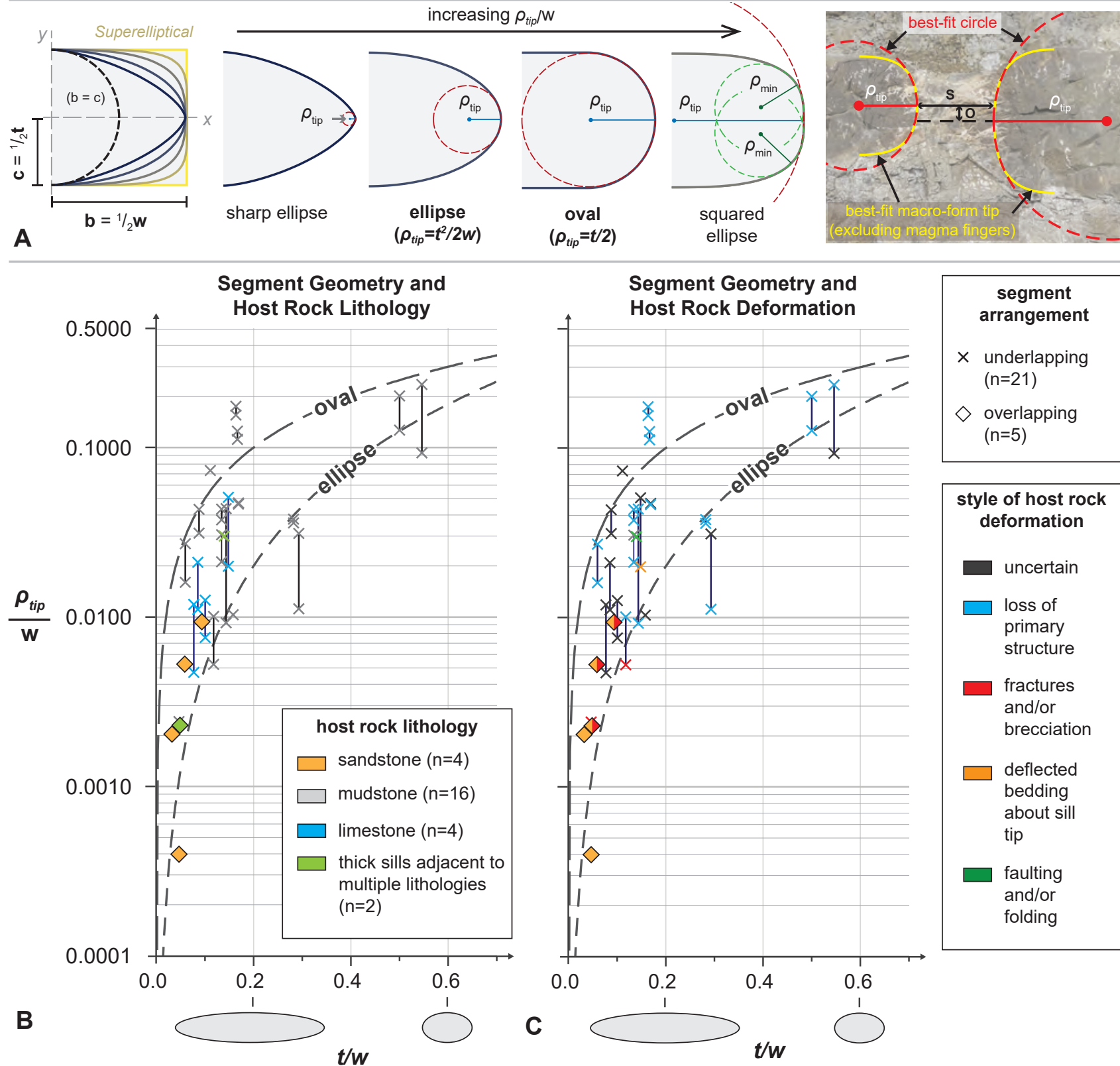

segment

underlapping $(n=21)$

$\diamond$ overlapping $(n=5)$

style of host rock deformation

uncertain

loss of primary structure

$\square$ fractures and/or brecciation

deflected bedding about sill tip

faulting and/or folding

Figure 6: Geometrical characterisation of sill segment geometries in the Neist Point study area. [A] Schematic diagram to illustrate circular through to squared tip geometries and how the macro-tip form radius of curvature ( $\rho_{\text {tip }}$; red circle) was measured, with a worked field example. Note that once tip geometry surpasses an oval, corners develop and the superelliptical geometry can also be defined by two minimum radii of curvature (see green circles in "squared ellipse" example); however only the macro-form tip geometry $\left(\rho_{\text {tip }}\right)$ is used here. Following the method of Pollard et al. [1975] the macro-tip forms were plotted and colour-coded to show: [B] segment geometry and host rock lithology; [C] segment geometry and observed style of localised host rock deformation ahead of the tip. Dashed lines for idealised oval and elliptical geometries are shown for comparison to measured geometries. Individual segments are shown as two data points (denoting the geometry of each tip) connected by a line; line length correlates to the segment asymmetry about its c-axis (longer line = more asymmetric); single (unconnected) points are where only one tip could be measured. Symbols indicate segment arrangement (underlapping or overlapping). Note that schematic segments below the $\mathrm{x}$-axis in $[\mathrm{B}]$ and $[\mathrm{C}]$ are to illustrate segment $t / w$ ratio only. (Data available in Supplementary File 2).

ments) also occur, and include fractures, faults, and intrusive sheets that cross-cut the relay zone (Figure 8AE). The angle of secondary structures $(\alpha)$ was measured from the plane of the intrusive segment to the plane of the structure (after Tentler and Acocella [2010]). In the measured overlap zones the angle of secondary 

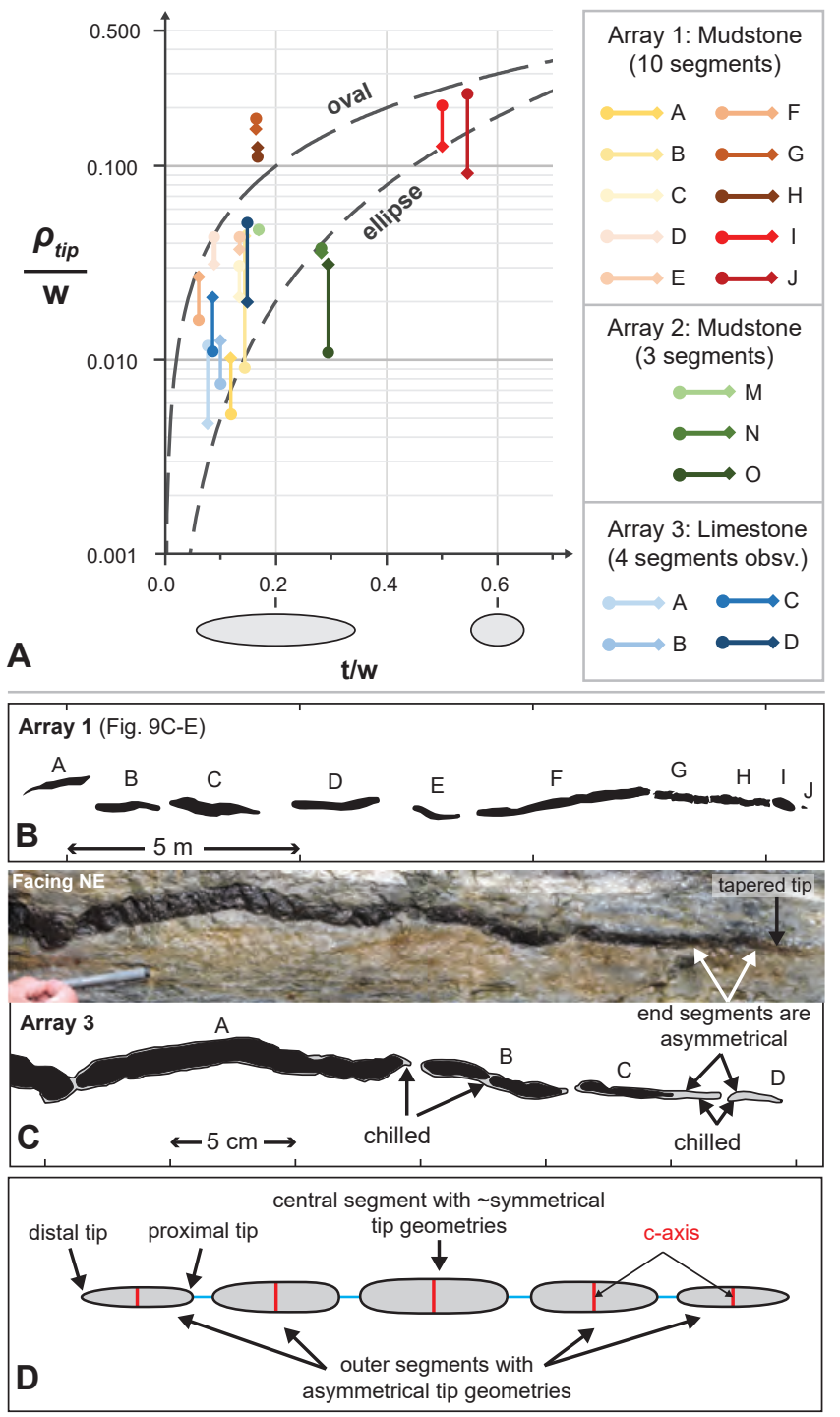

Figure 7: Geometrical characterisation of individual segment geometries within an array. [A] Plot to define segment geometries: segment tips are displayed as circles and diamonds (for left and right tips, as observed in outcrop), individual segments are shown as linked symbols and the line length correlates to segment asymmetry about its c-axis (longer line $=$ more asymmetric). Relay zones occur between the diamond and circle tips of adjacent segments (Data available in Supplementary File 2). Note that schematic segments below $\mathrm{x}$-axis are to illustrate segment $t / w$ ratio only. [B] Sketch of Array 1 , segments in mudstone; [C] Photo and sketch of Array 3, segments in limestone, only 4 segments were observed. [D] Illustration to show the generalised asymmetric geometry of collinear segments in an elastic medium (redrawn and modified from analogue model of Pollard et al. [1982]).

structures increases linearly with the amount of overlap (Figure 8G).

Underlapping segments also display multiple styles of host rock deformation in the underlap zone. Offset, underlapping segments in sandstone display relay zone cross-fractures and localised zones of breccia immediately ahead of segment tips (Figure 9A), as well as minor thrust faults and localised zones of structureless host rock ahead of segment tips (Figure 9B). Deformation in mudstone between offset underlapping segments includes fracturing, and some sill tips display irregular geometries with magma fingers protruding into the underlap zone (Figure 9C). Approximately collinear underlapping segments show a loss of primary host rock structure (e.g. bedding and laminations) in the underlap zone (Figure 9D-F). Segments display ellipse to squared ellipse tip geometries, and in most cases small magma fingers extend from the segment tip into the underlap zone towards the adjacent segment (Figure 9D-F). Linked collinear segments are identified by cusps of deformed host rock at the intrusion contact, similar to those observed by Pollard et al. [1975]. for collinear segments in the Shonkin Sag sill, Montana, emplaced into interbedded sandstone and shale units.

Figure 10 shows an approximately $7 \mathrm{~m}$ thick and 51 $\mathrm{m}$ wide sill segment with an approximately circular tip geometry. Host rock xenoliths occur close to the upper contact of the thick sill segment (Figure 10A), however limited accessibility made it impossible to determine whether these xenoliths are the result of stoping, host rock lenses between stacked sills, or remnant relay zones between linked sill segments. A fold and thrust zone occurs at the western tip (Figure 10A). Host rock deformation is most intense immediately ahead of the sill tip (within $\sim 2 \mathrm{~m}$; Figure 10B-C), and the deformation intensity decays over a distance of approximately $10 \mathrm{~m}$ (equivalent to $20 \%$ of the segment width). Immediately ahead of the sill tip, minor thrust faults accommodate local horizontal shortening and vertical extension (Figure 10B-C); material stacking has caused the thickness of the host rock package to increase by $\sim 49 \%$ at the sill tip compared to that at a distance of $\sim 20 \mathrm{~m}$ from the sill tip. Ahead of the sill tip major thrust faults (those with lengths $>5 \mathrm{~m}$ ) dip away from the sill tip, suggestive of material movement towards and over the sill segment. Minor conjugate thrust fault pairs are also observed at the major thrust faults (Figure 10D-E). Note that no thrust faults, or significant folding of the host rock, are observed above the intrusion (Figure 10A).

\subsection{Segment arrangement and host rock deformation}

Various styles of host rock deformation and tip geometries were observed throughout the study area, associated with different tip geometries and segment arrangements. We can assess whether segment tip geometry and style of host rock deformation correlate to the spatial relationship between adjacent segments by plotting the separation and offset for each measured re- 

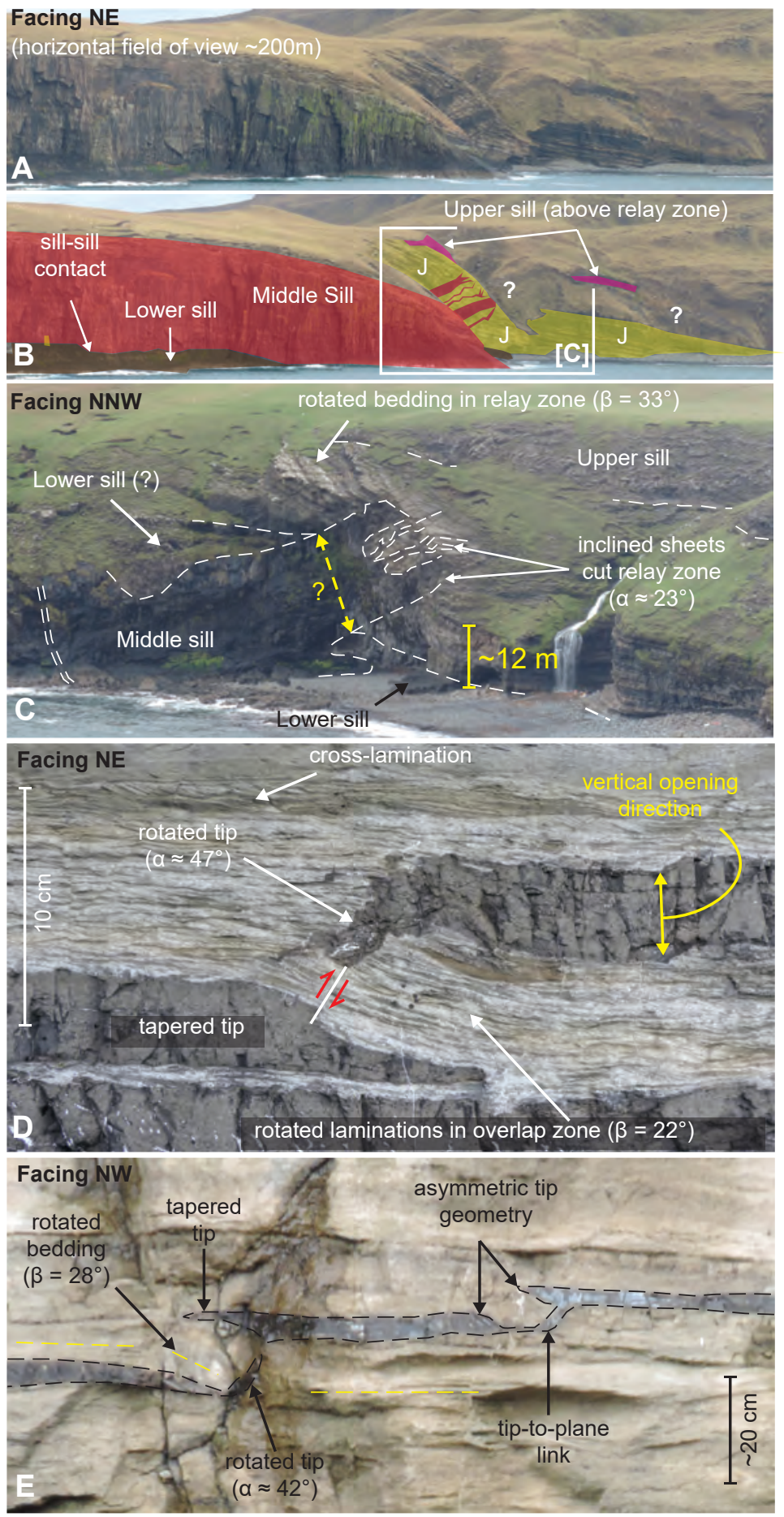
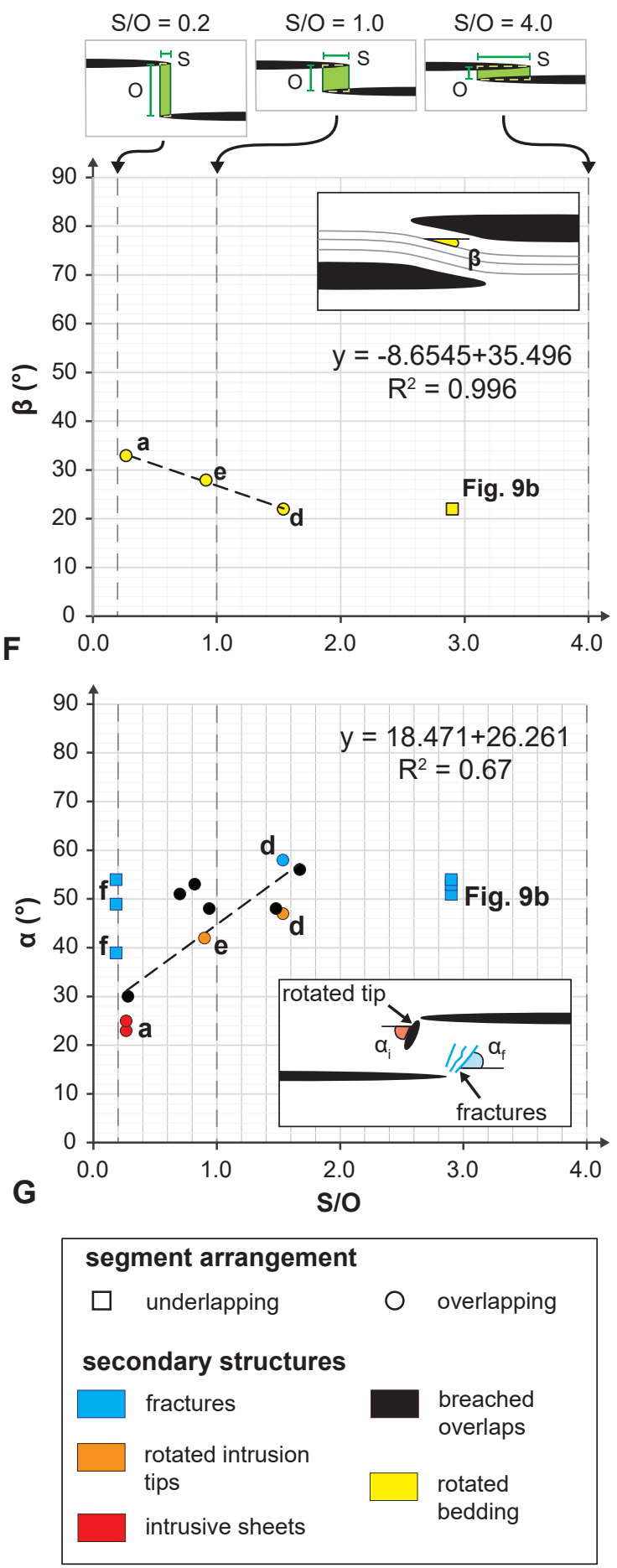

Figure 8: (Caption next page.)

lay zone akin to methods used for dyke and fault analysis [e.g. Delaney and Pollard 1981; Long and Imber 2011; Fossen and Rotevatn 2016], and comparable to the work of Delaney and Pollard [1981]. Collectively, our data spans almost five orders of magnitude for segment offset, ranging from the millimetre to tens-ofmetre scale. All observed overlapping sill segments in the Neist Point study area have asymmetrical tapered tips (and tapered abandoned tips at breached overlaps)
(Figure 8; and A-B on Figure 11A). Only three of the measured overlap zones are intact (i.e. not breached, e.g. Figure $8 \mathrm{D}-\mathrm{E}$ ), and together with the breached overlap zones they fit a positive near-linear power-law regression with an $\mathrm{R}^{2}$ value of 0.83 (Figure $11 \mathrm{~A}$ ), suggesting that overlapping segments follow elastic-brittle propagation mechanisms.

Underlapping segments, however, display elliptical to squared ellipse tip geometries at high relay zone as- 
Figure 8: (Previous page.) Examples of offset overlapping segments in the study area. Overlap zones have comparable geometries across several orders of magnitude. [A]-[C] Tens-of-metre scale relay in interbedded sedimentary host, yellow arrow in [C] suggests the opening direction; Jurassic bedding is rotated in the overlap zone between two thick sills; sheets emanate from the lower sill tip and cut the relay zone. [D] Centimetre-scale relay in sandstone; laminations are rotated between overlapping tips, fractures also cut the relay zone; the upper tip is rotated downwards towards the lower segment. [E] Centimetre-scale relays in sandstone; overlap zone between left and central segments displays rotated bedding and the lower segment has a rotated tip; the central and right segments form a tip-to-plane breached relay. [F] Graph to show rotation angle of bedding $(\beta)$ in relay zones, plotted against relay aspect ratio (Separation/Offset); dashed line shows best-fit negative linear regression for overlap zones; underlap data is insufficient to determine a reliable relationship. [G] Graph to show the angle of secondary structures $(\alpha)$ within relay zones (i.e. fractures, rotated tips, or intrusive sheets), measured from the segment plane to the structure, plotted against relay zone aspect ratio (Separation/Offset); dashed line shows a best-fit positive linear regression for overlapping segments; underlap data is insufficient to determine a reliable relationship. Note, in $[\mathrm{H}]$ and $[\mathrm{l}]$, underlapping segments are plotted with positive $\mathrm{S} / \mathrm{O}$ values. (Unannotated photos $[\mathrm{A}]-[\mathrm{E}]$ available in Supplementary File 1, data for [F]-[G] available in Supplementary File 2).

pect ratios (C-D on Figure 11A), and approaching low relay zone aspect ratios (E on Figure $11 \mathrm{~A})$. Where the underlap is relatively large (e.g. C on Figure 11A has a 20:1 aspect ratio), the zone of host rock deformation is localised about each segment tip and does not extend across the entire underlap zone. For relatively small underlaps (e.g. D on Figure 11A has a 5:1 aspect ratio) deformation is continuous across the underlap zone; minor magma fingers are observed extending from the adjacent sill tips into this zone. We find that underlapping segments display a poor positive correlation between separation and offset $\left(R^{2}=0.30\right.$ : Figure $\left.11 \mathrm{~A}\right)$, which we attribute to the fact that underlapping segments may stop propagating at any given separation, which is not primarily controlled by the offset.

\section{Discussion}

\subsection{Controls on sheet intrusion tip geometry}

Intrusive segment tip geometry and the mechanism of magma propagation are commonly inferred to reflect the mechanical properties of the host rock at the time of initial magma emplacement [e.g. Schofield et al. 2010; 2012; Schmiedel et al. 2017; Spacapan et al. 2017; Vachon and Hieronymus 2017; Bertelsen et al. 2018; Kjøll et al. 2019; Schmiedel et al. 2019]. These emplacement models are based on field observations, which preserve the final stage of intrusion, and scaled laboratory modelsthat reflect magma propagation under controlled conditions where specific variables can be modified with each experiment [e.g. Abdelmalak et al. 2012; Galland et al. 2014; Bertelsen et al. 2018; Poppe et al. 2019]. There is, however, the potential for post-emplacement and/or late-stage synemplacement overprinting, in which case the preserved growth mechanism may not be representative of intrusion growth as a whole (see e.g. Spacapan et al. [2017] and Haug et al. [2017]). We can consider the potential for post-emplacement overprinting through detailed field-based textural and structural characterisation of the host rock and intrusion [e.g. Bons et al. 2004]. Few studies have focused on syn-emplacement variations in host rock and magma properties, which may cause a transition in the intrusion tip geometry and emplacement mechanism [Poppe et al. 2020]. Segments with tapered to squared ellipse (superelliptical) tip geometries are exposed in the Neist Point study area, with no correlation between host rock lithology and emplacement mechanism (Figures 8, 9 and 10). Similar ranges of segment tip geometries are also observed in other intrusive complexes (e.g. Figure 2). At Neist Point, examples of tapered sill tips are associated with host rock bending, and demonstrate emplacement through elastic-brittle processes, at least at the scale of observation (e.g. Figure 8). Elliptical to squared ellipse (superelliptical) geometries are associated with several styles of localised host rock deformation ahead of isolated tips and between adjacent segments, including brecciation (Figure 9A-B); a loss of host rock structure, where in some cases magma fingers protrude from the segment tips into this zone (Figure 9D-F), akin to models of fluidisation [e.g. Schofield et al. 2012]; and shearband formation (Figure 10), comparable to models of bulldozing and viscous indentation [e.g. Spacapan et al. 2017].

Differences in host rock deformation style may reflect the initial host rock shear cohesion and tensile strength [Baer 1991; Poppe et al. 2019]. Lithologies with higher shear cohesion are more likely to localise strain into a single fracture, whereas those with low cohesion are not able to withstand elevated shear stresses and will fail through distributed fracture along grain boundaries; with increased fluid pressure, disaggregation can lead to fluidisation. The scale of the zone of brecciation and fluidisation may therefore relate to the scale of existing discontinuity within the material. In a mudstone, this is the grain size, and in intercalated units (mudstone-sandstone sequences for instance), this may be the layer thickness; in the case of lavas and preexisting sills, this may be the cooling joint network. All 

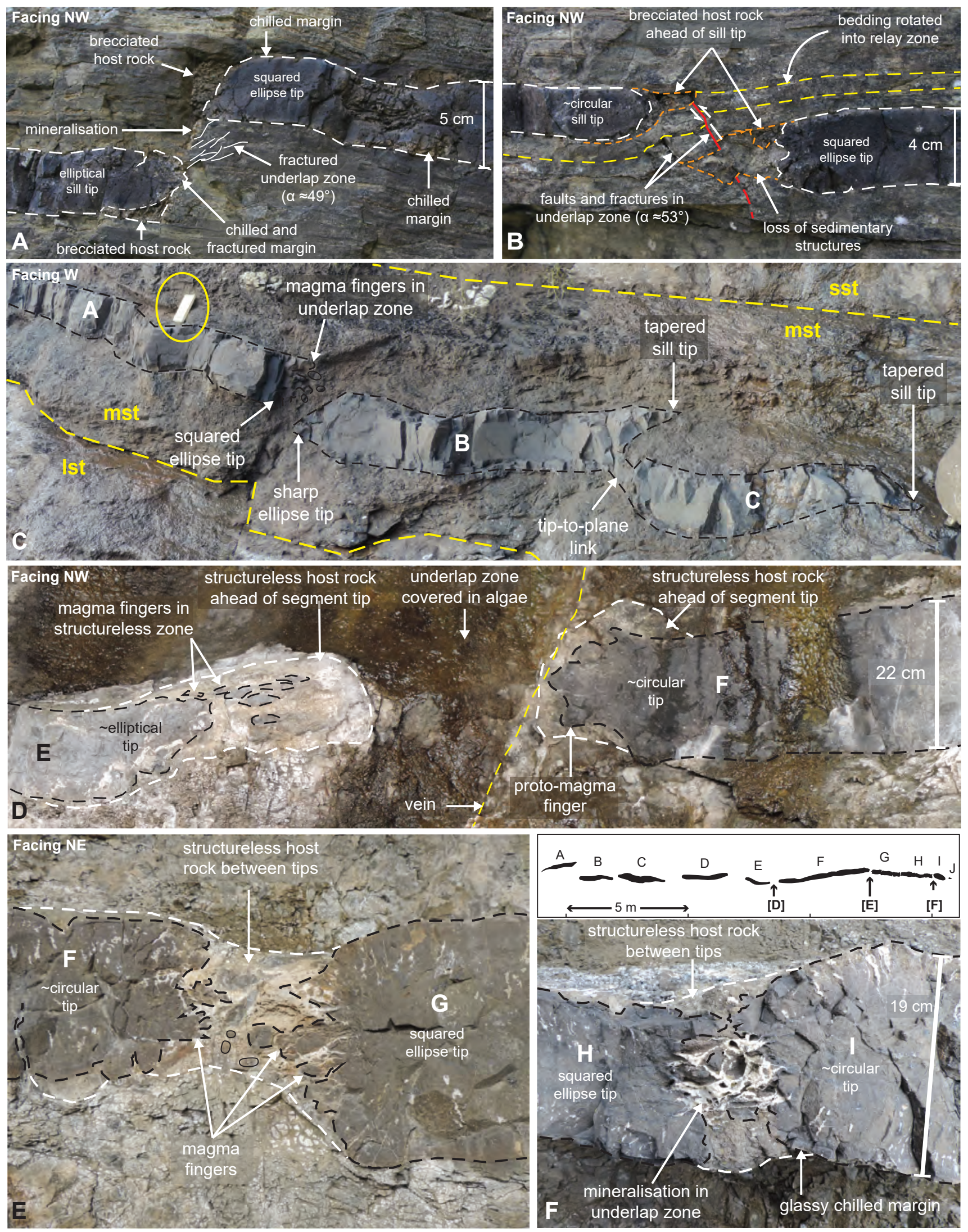

Figure 9: (Caption next page.) 
Figure 9: (Previous page.) Examples of underlapping segment arrays in the Neist Point study area. $[A]-[B]$ Offset underlapping segments with elliptical to squared ellipse geometries in laminated sandstone: [A] segments have chilled margins; brecciated and fractured host rock occurs ahead of each tip and within the relay zone. [A] Brecciation and loss of host rock structure within the relay zone. [C] Offset segments in mudstone, segments are labelled $A-C$. Underlapping segments display squared ellipse tips with magma fingers $(A)$ and sharp ellipse (B) geometries. Offset overlapping linked segments (B-C) display tapered (wedge-shape) tips. [D]-[F] Examples of underlapping collinear segments in mudstone, their position in the array is shown on the sketch. [D] Elliptical (E) to circular (F) tip geometries, the zone of lighter coloured structureless host rock is localised about each tip; magma fingers protrude from the segment tips into the structureless zone. [E] Elliptical (F) to squared ellipse (G) tip geometries, magma fingers protrude from the segment tips into the structureless underlap zone. [F] squared ellipse $(\mathrm{H})$ and circular $(\mathrm{I})$ tip geometries magma fingers protrude from the segment tips into the structureless underlap zone. (Unannotated photos available in Supplementary File 1).

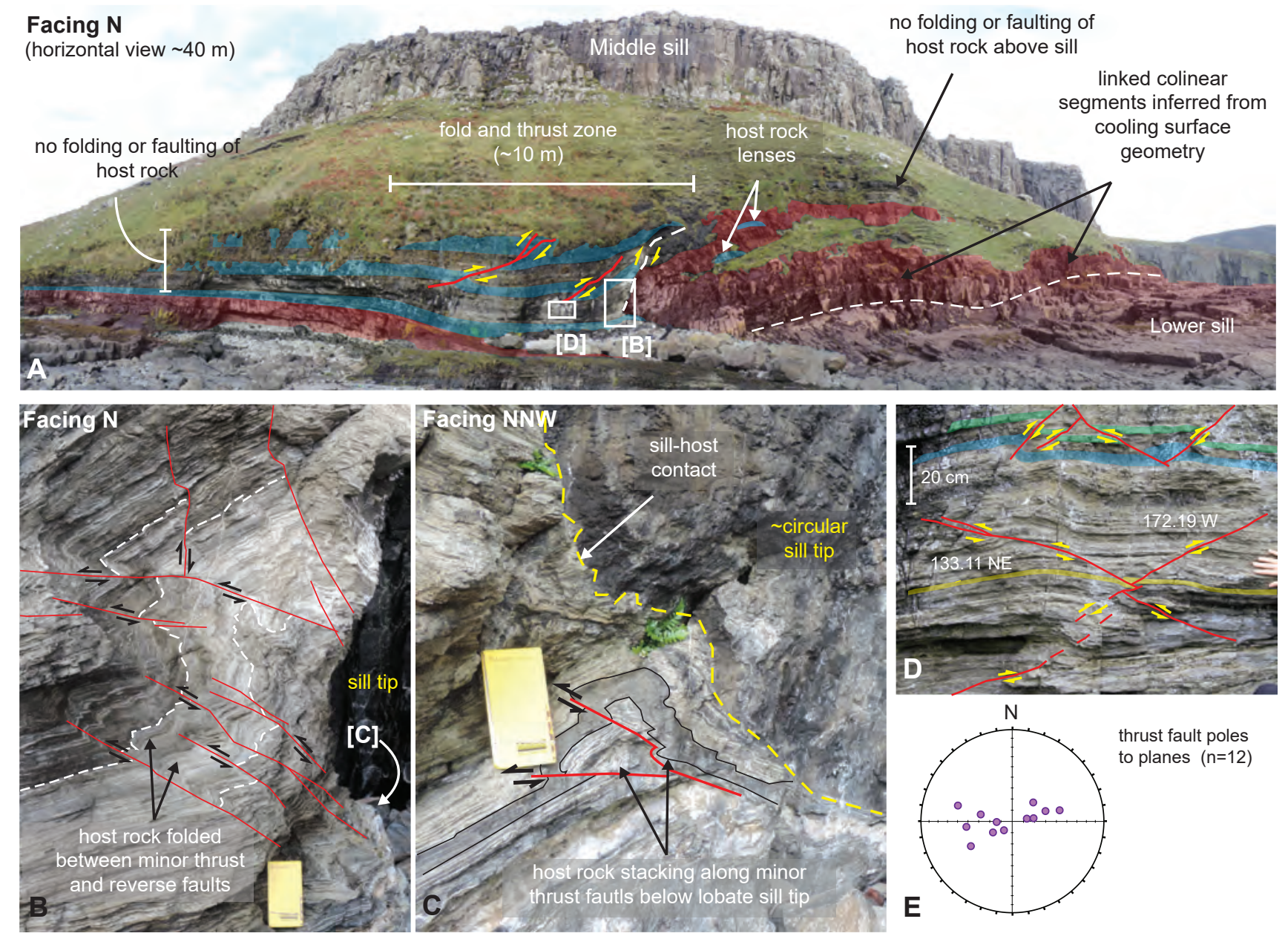

Figure 10: Fold and thrust zone ahead of a thick sill with a circular tip (Location shown on Figure 4). [A] Fold and thrust zone ahead of sill segment (highlighted red); marker units are highlighted blue. Major thrust faults verge towards the sill segment; exposed host units above the segment are not folded or faulted. [B] Minor thrust and reverse faults at the sill-host contact; notebook for scale. [C] Host rock stacking across thrust faults below the tip; notebook for scale Centimetre-scale conjugate thrust faults below one of the major thrust faults. [D] Minor thrust and reverse faults ahead of the sill-host contact; notebook for scale. (Unannotated photos [A]-[D] available in Supplementary File 1). [E] Equal-area lower-hemisphere stereonet with thrust faults ahead of the sill tip plotted as poles to planes (Data available in Supplementary File 2). 

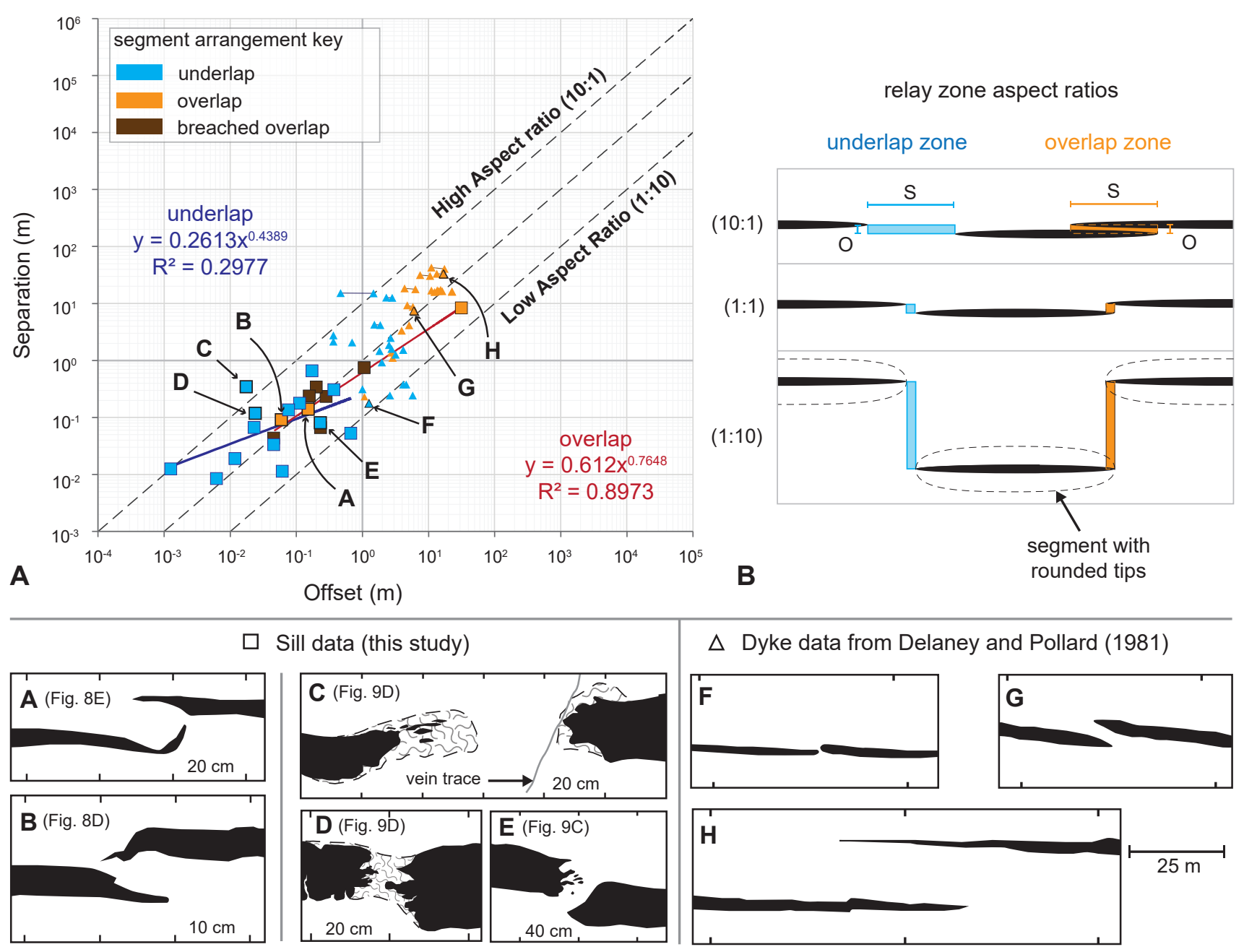

Figure 11: Geometrical characterisation of relay zone aspect ratios between measured sill segments (Data available in Supplementary File 2). [A] Log-Log plot to show relay zone aspect ratios of underlapping (blue squares) and overlapping (orange squares) sill segments in the Neist Point study area; collinear segments are not shown as zero-values cannot plot on a log-scale. Low and high aspect ratio lines are from Long and Imber [2011]. Note that underlapping segments are plotted with positive values. Best fit power law regressions are fitted to the underlapping (blue line) and overlapping (red line) segments. The sill relay zone data is also plotted with published relay zone data for dykes intruded into shale at Ship Rock, New Mexico (triangles). The data was manually digitised from Delaney and Pollard [1981, their Figure 10] using WebPlotDigitizer, and replotted. [B] Illustrations of high (10:1), unity (1:1), and low (1:10) aspect ratios for underlapping and overlapping segments; separation, S; offset, 0. Segment sketches A-E were drawn from examples in the Neist Point study area: A-B, overlapping and interacting; $C-E$, underlapping segments with rounded to blunt tips and minor magma fingers. Sketches of segment tip geometries $\mathrm{F}-\mathrm{H}$ are redrawn from Delaney and Pollard [1981, their Figure 10]: $\mathrm{F}$, underlapping segments with rounded tips; $G$, slightly overlapping segments with asymmetrical tips, indicative of interaction; $H$, overlapping segments with symmetrical tapered tips, indicative of no segment interaction.

of the observed segments associated with disaggregated (brecciated or fluidised) host rock have elliptical to superelliptical tip geometries. Brecciation and fluidisation both act to reduce host rock shear cohesion and tensile strength to zero. Material with low or zero cohesion cannot support tensile stress concentrations; instead, tensile stresses are dissipated as plastic deformation ahead of the intrusion tip [e.g. Mathieu et al. 2008; Bertelsen et al. 2018]. Tensile failure is therefore inhibited, and the segment tip may inflate to accommodate the driving pressure, producing a rounded tip geometry [e.g. Cañón-Tapia and Merle 2006].

Few studies have documented the presence of tapered and rounded segment geometries in the same study area [exceptions include Baer 1991; Kjøll et al. 2019; Poppe et al. 2020]. Baer [1991] suggests that dykes may propagate in a poorly cemented sandstone by a cyclic process of brittle fracture and viscous fingering that depends on the availability of magma-related fluids and local resistance of the host rock to fluidisa- 
tion. Alternatively, Kjøll et al. [2019] report a 2-stage process to account for dyke geometries in the Scandinavian Caledonides; an earlier set with tapered tips and a later set with rounded tips. They suggest that the later set resulted from magma emplacement into a ductile host due to the thermal effects of the first dyke set locally raising the brittle-ductile transition. Wilson et al. [2016] also suggest a two-stage emplacement model for the Trachyte Mesa intrusions, Henry Mountains, Utah similar to models of Hunt et al. [1953] and Corry [1988]: initial elastic-brittle fracture propagation followed by segment inflation, tip-rounding and associated shear failure of the host rock. In this model, shear failure is caused by overburden flexure and bending once the sill reaches a critical diameter in relation to emplacement depth. The examples presented in our study do not resemble cyclic emplacement processes since the host rock deformation is localised ahead of isolated segment tips, or between adjacent segments. Additionally, the presence of sharp intrusion contacts, linked overlapping segments with tapered abandoned tips, and non-linked segments with tapered tips and deflected host rock bedding provides evidence for magma propagation via elastic-brittle processes, indicating that the host rock in the Neist Point study area was able to deform via elastic brittle fracture. We observe variations in sill tip geometry and styles of host rock deformation, for segments varying from $\mathrm{cm}$ to tens-of-metre thickness, suggesting that the depth of emplacement and segment size do not necessarily control the final (preserved) geometry or local style of deformation at the segment tip.

Dynamic changes during magma emplacement may modify the properties of the magma and host rock ahead of the propagating tip. Magma viscosity may increase due to cooling, crystallisation (and generation of crystal mush), or vesiculation and degassing [e.g. Shaw 1969; Johnson and Pollard 1973; Hess and Dingwell 1996; Currier and Marsh 2015; Chanceaux and Menand 2016]. Host rock rheology and cohesion may be altered due to local heating and volatile loss [e.g. Aarnes et al. 2011a; b; Annen 2011; Currier and Marsh 2015; Chanceaux and Menand 2016; Mattsson et al. 2018]; and localised pore fluid boiling may cause fracturing, brecciation, or fluidisation ahead of segment tips [e.g. Kokelaar 1982; Schofield et al. 2010; Poppe et al. 2020]. In their scaling parameters for comparison between natural and modelled intrusions, Galland et al. [2014] suggest that magma viscosity and host rock cohesion are coupled by the dimensionless ratio $(\eta v) /(C T)$, where $\eta$ is magma viscosity, $v$ is flow velocity, $C$ is cohesion, and $T$ is intrusion thickness. This provides a dynamic ratio between time-dependent viscous stresses in the flowing magma and stresses in the host rock, and indicates that increasing magma viscosity has the same effect as decreasing host rock cohesion: inhibits elastic-brittle propagation and promotes tip rounding. Such a modification and the associated host rock deformations would likely overprint any evidence of the initial brittle emplacement, field exposures displaying segments with tapered and superelliptical tips in the same intrusive complex could therefore be used to indicate late-stage modifications.

A transition from a tapered to rounded tip geometry would cause a change in the distribution of stress in the process zone, from a stress singularity at a tapered tip to distributed radial and circumferential stress ahead of an elliptical or oval tip [Pollard 1973; Souche et al. 2019]. The zones of maximum stress are concentrated at the corners $\left(\rho_{\min }\right)$ of superelliptical segments, which would likely propagate as viscous indenters causing shear failure of the host [Figure 9 and 10; e.g. Abdelmalak et al. 2012; Guldstrand et al. 2017; Haug et al. 2018; Walker et al. 2021]. As the radius of curvature of the corners decreases (i.e. toward a right angle) the stress becomes increasingly localised, and the stress concentration factor (i.e. the ratio of the maximum stress at the contact to the far-field stress: $\sigma_{\max } / \sigma^{\infty}$ ), tends towards infinity [Jaeger et al. 2007; Walker et al. 2021]. Propagation of segments with superelliptical to blunt tips, however, is inefficient [e.g. Pollard et al. 1975] Rounded segment tips at the extremities of intrusions, particularly where spatially associated with tapered segment tips such as those observed in Skye and other locations (e.g. Figure 2), are therefore unlikely to be representative of the initial stages of intrusion growth (i.e. more proximal to source) in a primarily cohesive (brittle) host rock that was capable of supporting localised stress concentrations. Instead, the rounded tips most likely developed later due to modifications to the conditions of emplacement.

\subsection{A model for segment evolution}

Sill segments in the Neist Point study area display tapered to squared ellipse tip geometries in the same host rock units, and a variety of associated local host rock deformation. Similar examples are also observed in other intrusive complexes (Figure 2); in each case the host rock likely had sufficient cohesion to support tensile fracturing and deform via elastic-brittle processes during initial magma emplacement. We acknowledge that in some cases magma may propagate consistently via non-brittle processes (e.g. in salt [Schofield et al. 2014]), however, the variety of segment tip geometries and deformation that we observe in the same host rock cannot be readily explained by current emplacement models, which generally involve a single propagation mechanism throughout the life of a segment. Here we present a conceptual model based on previous propagation models, and our observations of sill segment geometries and associated host rock deformation. We propose a multi-phase model for the evolution of intrusive segment geometry for a basaltic melt in an initially brittle host rock in the shallow crust. Our model accounts for changes to the local conditions of emplace- 


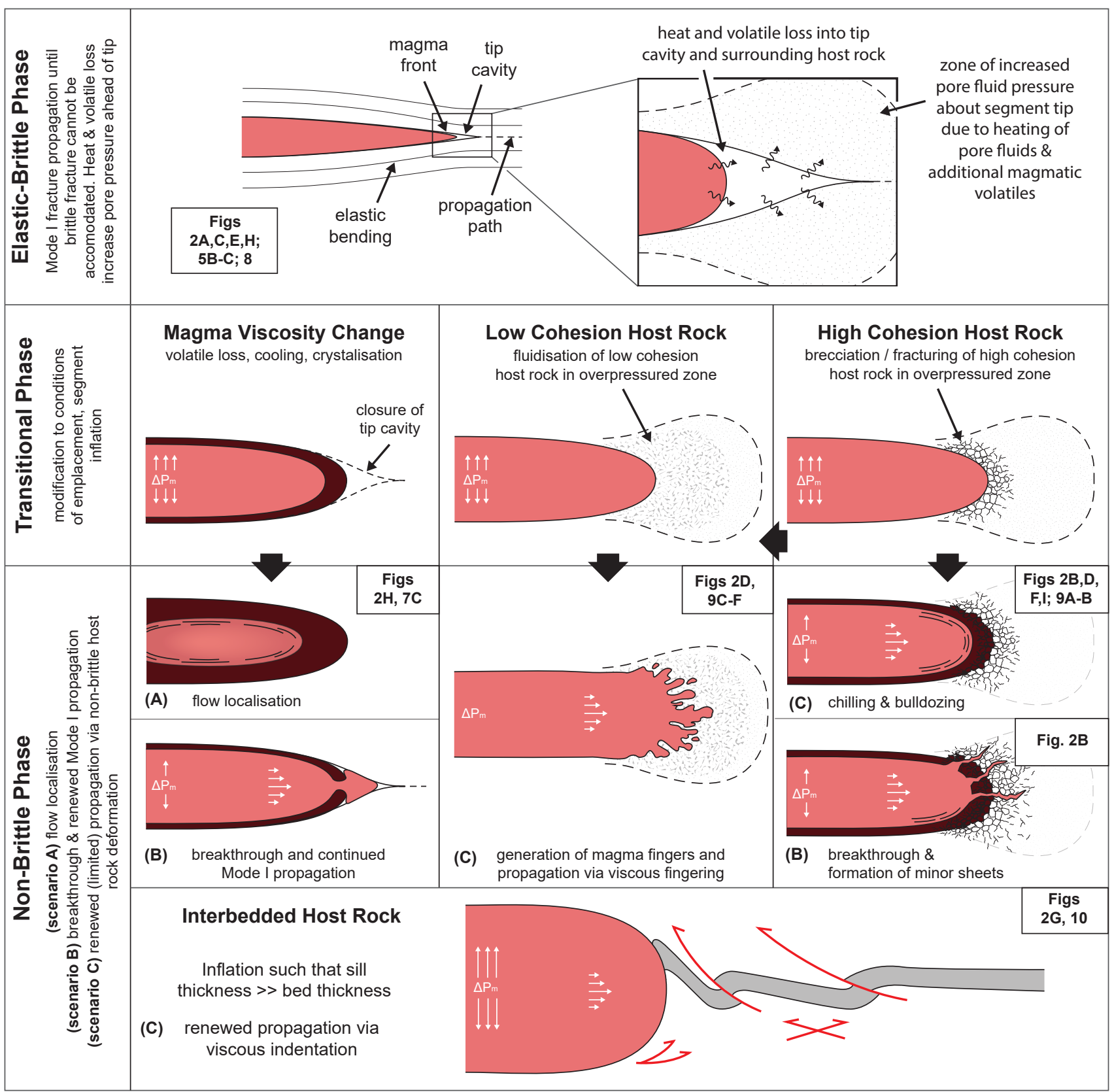

Figure 12: Conceptual model for evolution of collinear segments. [A] Stage I: Brittle propagation; [B] Stage II: local modification to the conditions of emplacement; driving pressure is accommodated predominantly by segment inflation. With increased fluid pressure, disaggregated (brecciated / fractured) high cohesion host rock could become fluidised, or disaggregated host may behave as a viscous medium. [C] Stage III: renewed limited propagation via non-brittle propagation mechanisms.

ment over the lifespan of the segment. We envisage the following phases:

Elastic-Brittle Phase: Magma emplacement, segmentation, and propagation as Mode I fractures (Figure 12); controlled by periods of driving pressure increase and relaxation following the theory of linear elastic fracture mechanics (LEFM) [e.g. Atkinson 1987; Cañón-Tapia and Merle 2006]. The propagating parent sheet may segment along its tip-line due to material anisotropy, exploitation of preferentially oriented pre-existing discontinuities (e.g. joints, fractures, bedding, foliation), rotation of the minimum principal stress axis, or viscosity contrasts between the magma and host rock [e.g. Pollard et al. 1975]. Additionally, non-optimally oriented discontinuities (i.e. those with planes oriented oblique to the minimum compressive stress axis) may also be dilated if the magma pressure is sufficiently high [Martínez-Poza et al. 2014; Stephens et al. 2018]. 
During this phase, segments will propagate until the driving pressure is unable to facilitate the next increment of growth; for lateral segment propagation this is likely due to local competition for the available mechanical energy between offset and/or collinear adjacent segments [e.g. Pollard et al. 1975], or due to a drop in driving pressure as a function of the increasing segment length for frontal tip propagation. The segment likely accrues the majority of its length and width during this phase, with a proportional increase in thickness.

Transitional Phase: We infer localised modifications to the conditions of emplacement (Figure 12). This may include modifications to the magma viscosity due to, for example volatile loss, degassing, cooling, and crystallisation, and/or local modifications to the host rock mechanical properties due heat transfer and/or volatile loss from the magma (increasing the pore fluid pressure ahead of the segment tip). High porosity and/or low cohesion host rock may be fluidised during this stage, whereas cohesive host rock may be fractured or brecciated ahead of the segment tip [Baer 1991]. Magma degassing, cooling, and crystallisation cause magma rheology to evolve from viscous to viscoelastic to brittle once chilled [Dingwell 2006]. During the transition the resistance to flow is increased, which dissipates mechanical energy as viscous drag [Pollard et al. 1975; Rubin 1993]. The chilled margin may have a higher tensile strength than the host rock, meaning a larger driving pressure would be required to re-establish elasticbrittle propagation [Dingwell 2006; Currier and Marsh 2015]. Depending on the cooling rate relative to the rate of increasing driving pressure, magma flow may become localised into the centre of the segment, cause segment inflation or breaching somewhere along the intrusion, or propagation may cease altogether, in which case the primary tapered tip geometry is preserved [Figure 2H, Figure 7C; Chanceaux and Menand 2016]. This phase is therefore associated with stalled propagation, segment inflation, and a change in tip geometry. We envisage minimal change to the segment width during this phase, as the driving pressure is accommodated by segment inflation without further propagation.

Non-Brittle Phase: Non-brittle propagation and/or termination. Three scenarios are envisaged for this phase (Figure 12): (A) flow localisation, (B) breakthrough of the chilled margin to enable resumed Mode I propagation, or $(\mathrm{C})$ renewed propagation via nonbrittle mechanisms (e.g. viscous indentation, bulldozing, or fluidisation). Segment tip rounding during the Transitional Phase modifies the local tip stress distribution from a tensile stress concentration to a circumferential tension with radial compression and shear stress concentration. When the width exceeds the thickness of a lobate segment (i.e. a segment aspect ratio (thickness/width) $<1$ ), the shear stress concentrations at the tip may facilitate propagation via bulldozing or viscous indentation [Pollard et al. 1975; Rubin 1993; Souche et al. 2019]. Local host rock fluidisation may enable instigation of a Saffman-Taylor instability at the magmafluidised host rock interface, for renewed propagation via viscous fingering [Saffman and Taylor 1958; Pollard et al. 1975]. Segment linkage through a locally fluidised zone may result in a 'cusp' of deformed host rock preserved at the intrusion contact, enabling identification of this mechanism [Pollard et al. 1975]. Notably, the renewed propagation mechanism will vary on a segmentby-segment basis, dependent on the changes that occur. Multiple tip geometries and styles of host rock deformation could, therefore, occur in the same host rock units and across a single intrusive complex.

Any further propagation will be governed by the magma driving pressure and may be recorded by changes in orientation of flow indicators such as mineral fabrics or surface textures on the intrusion [e.g. Galland et al. 2019; Martin et al. 2019]. We expect the non-brittle propagation distance to be relatively minor due to the increased stress distribution and inefficiency of shear propagation of a rounded or blunt segment tip relative to a tapered tip (Mode I fracture) [Inglis 1913; Pollard et al. 1975; Walker et al. 2021]. Unless the driving pressure increases significantly to generate a break-out and continued Mode I propagation ([e.g. Baer 1991; Currier and Marsh 2015]: Figure 12, Scenario B), or the magma is able to exploit preferentially oriented structures ahead of the segment tip (such as faults [e.g. Spacapan et al. 2017]) (in which case the process may revert back to the Elastic-Brittle Phase of emplacement), in our model renewed propagation via non-brittle mechanisms represents the final stage in the life of the segment. Hence, the preserved tip-zone deformation may not be representative of the initial propagation mechanism that controlled the main phase of segment growth.

\subsection{Three-dimensional applications}

Two-dimensional outcrop sections (such as Neist Point) that contain multiple intrusive segments are inferred to represent a cross-section perpendicular to the main flow direction [e.g. Magee et al. 2016]. These segments should link to a parent sheet either into or out of the section view. Magma propagation models (Figure 1) are typically inferred to represent the bulk propagation direction of the frontal segment tip (i.e. propagation parallel to segment length); a question therefore arises as to how these models translate to propagation of the lateral segment tip line, particularly since interaction of adjacent segments may influence the intensity of deformation [e.g. Galland et al. 2019]. In the Neist Point study area we observe multi-segment arrays and isolated segment tips (those not adjacent to another segment). Adjacent underlapping segments display sharp ellipse to squared ellipse tip geometries (Figure 9), while isolated segment tips show tapered to circular geometries (Figure 7B-C, Figure 10A). Al- 
though local changes in host rock properties may be enhanced between interacting adjacent segments, the field evidence suggests that our model is applicable to any point along the segment tip line, particularly once the main phase of segment growth has ceased.

Our proposed model provides an evolutionary pathway for magmatic segments that do not link during their initial brittle propagation. The timescale of tip geometry evolution is dependent on the rate of change to the host rock and/or magma properties. Our model is consistent with observations of sills and dykes ranging from centimetre to tens of metre thickness and emplaced in the brittle crust (up to $\sim 2 \mathrm{~km}$ depth), so should therefore be consistent with the development of large intrusive complexes, as imaged in subsurface seismic surveys. Importantly, this model provides an explanation as to how multiple styles of host rock deformation, and seemingly multiple propagation mechanisms, occur in a single field area.

Our model applies to emplacement of low viscosity (basaltic) melts emplaced at shallow depths into an initially cohesive, elastic material. We note that intrusion of higher viscosity melts (e.g. rhyolite) or magma emplacement at greater confining stresses can cause the initial tip geometry and/or the mechanism of initial host rock deformation to vary from our model. However, in these cases an evolving pathway also occurs [e.g. Currier and Marsh 2015; Mattsson et al. 2018; Burchardt et al. 2019], which is consistent with our findings here.

\section{Conclusions}

We present a quantitative geometrical characterisation of a segmented basaltic sill network in the Little Minch Sill Complex, Isle of Skye, UK. Intrusive segments display tip geometries varying from tapered through to squared ellipses. Multiple styles of host rock deformation were observed from those consistent with elastic-brittle fracture, associated with tapered sill tips, to those consistent with non-brittle propagation models: fluidisation, brecciation, and viscous indentation. Our observations suggest that the emplacement mechanism may evolve over the active magmatic lifespan of the segment. We present a conceptual multi-phase emplacement model to account for the variety of segment geometries and styles of host rock deformation observed, the model comprises: an elastic-brittle phase, a transitional phase with localised modifications to the conditions of emplacement, and a non-brittle phase. Non-brittle propagation is likely minor relative to its preservation potential in the rock record: it is representative of the final stages in the life of the segment prior to complete crystallisation.

\section{Acknowledgements}

This work was undertaken during T.L. Stephens's PhD studentship at the University of Leicester, supported by the Central England Natural Environmental Research Council (NERC) Training Alliance (CENTA) (award reference: 1503848). The authors would like to thank Mitch Miller for assisting with fieldwork. Thanks are also extended to Steffi Burchardt and Richard England for their constructive comments on an earlier version of the manuscript, which led to significant improvements. We would also like to thank the Volcanica editor Pete Rowley, along with Sam Thiele and an anonymous reviewer for their constructive reviews, and Sam Poppe for kindly providing comments on the pre-print manuscript, all of which led to an improved final version.

\section{Author COntributions}

Field data and photographs from were collected by TLS, RJW, $A B$, and $\mathrm{DH}$. RJW and $A B$ provided valuable discussions in the field, as well as during manuscript preparation, along with DH. TS prepared the manuscript with contributions from all co-authors.

\section{Data AVAILABility}

The data used for this study is available in the supplementary files alongside the online version of this article; DoI: $10.30909 / \mathrm{vol} .04 .02 .203225$.

\section{COPYRIGHT NOTICE}

(C) The Author(s) 2021. This article is distributed under the terms of the Creative Commons Attribution 4.0 International License, which permits unrestricted use, distribution, and reproduction in any medium, provided you give appropriate credit to the original author(s) and the source, provide a link to the Creative Commons license, and indicate if changes were made.

\section{REFERENCES}

Aarnes, I., K. Fristad, S. Planke, and H. Svensen (2011a). "The impact of host-rock composition on devolatilization of sedimentary rocks during contact metamorphism around mafic sheet intrusions". Geochemistry, Geophysics, Geosystems 12 (10). DoI: 10 . 1029/2011gc003636.

Aarnes, I., H. Svensen, S. Polteau, and S. Planke (2011b). "Contact metamorphic devolatilization of shales in the Karoo Basin, South Africa, and the effects of multiple sill intrusions". Chemical Geology 281 (3-4), pp. 181-194. DoI: $10.1016 / \mathrm{j}$. chemgeo . 2010.12 .007 . 
Abdelmalak, M., R. Mourgues, O. Galland, and D. Bureau (2012). "Fracture mode analysis and related surface deformation during dyke intrusion: Results from 2D experimental modelling". Earth and Planetary Science Letters 359-360, pp. 93-105. DoI: $10.1016 / \mathrm{j}$. epsl.2012.10.008.

Ágústsdóttir, T., J. Woods, T. Greenfield, R. G. Green, R. S. White, T. Winder, B. Brandsdóttir, S. Steinthórsson, and H. Soosalu (2016). "Strike-slip faulting during the 2014 Bárðarbunga-Holuhraun dike intrusion, central Iceland". Geophysical Research Letters 43 (4), pp. 1495-1503. DoI: 10.1002/2015gl067423.

Angkasa, S. S., D. A. Jerram, J. M. Millett, H. H. Svensen, S. Planke, R. A. Taylor, N. Schofield, and J. Howell (2017). "Mafic intrusions, hydrothermal venting, and the basalt-sediment transition: Linking onshore and offshore examples from the North Atlantic igneous province". Interpretation 5 (3), SK83SK101. DoI: 10.1190/int-2016-0162.1.

Annen, C. (2011). "Implications of incremental emplacement of magma bodies for magma differentiation, thermal aureole dimensions and plutonism-volcanism relationships". Tectonophysics 500 (14), pp. 3-10. Dor: 10.1016/j . tecto . 2009.04.010.

Atkinson, B. K. (1987). "Introduction to fracture mechanics and its geophysical applications". Fracture mechanics of rock, pp. 1-26.

Baer, G. (1991). "Mechanisms of dike propagation in layered rocks and in massive, porous sedimentary rocks". Journal of Geophysical Research 96 (B7), p. 11911. DOI: $10.1029 / 91 \mathrm{jb} 00844$.

Barenblatt, G. (1962). "The Mathematical Theory of Equilibrium Cracks in Brittle Fracture". Advances in Applied Mechanics. Ed. by H. L. Dryden, T. von Kármán, G. Kuerti, F. H. van den Dungen, and L. Howarth. Vol. 7. Elsevier, pp. 55-129. ISBN: 9780120020072. DOI: $10.1016 / \mathrm{s} 0065-2156(\odot 8)$ 70121-2.

Bertelsen, H. S., B. D. Rogers, O. Galland, G. Dumazer, and A. Abbana Benanni (2018). "Laboratory Modeling of Coeval Brittle and Ductile Deformation During Magma Emplacement Into Viscoelastic Rocks". Frontiers in Earth Science 6. DoI: 10.3389/feart. 2018. ๑0199.

Biggs, J., E. Anthony, and C. Ebinger (2009). "Multiple inflation and deflation events at Kenyan volcanoes, East African Rift". Geology 37 (11), pp. 979-982. Dor: 10.1130/g30133a.1.

Bons, P. D., E. Druguet, I. Hamann, J. Carreras, and C. W. Passchier (2004). "Apparent boudinage in dykes". Journal of Structural Geology 26 (4), pp. 625636. DoI: $10.1016 / \mathrm{j}$.jsg.2003.11.009.

Burchardt, S., T. Mattsson, J. O. Palma, O. Galland, B. Almqvist, K. Mair, D. A. Jerram, Ø. Hammer, and Y. Sun (2019). "Progressive Growth of the Cerro Bayo Cryptodome, Chachahuén Volcano, Argentina-Implications for Viscous Magma Emplace- ment". Journal of Geophysical Research: Solid Earth 124 (8), pp. 7934-7961. Dor: 10.1029/2019jb017543.

Cañón-Tapia, E. and O. Merle (2006). "Dyke nucleation and early growth from pressurized magma chambers: Insights from analogue models". Journal of Volcanology and Geothermal Research 158 (3-4), pp. 207220. DoI: 10.1016/j . jvolgeores. 2006.05.003.

Chambers, L. M. and M. S. Pringle (2001). "Age and duration of activity at the Isle of Mull Tertiary igneous centre, Scotland, and confirmation of the existence of subchrons during Anomaly 26r". Earth and Planetary Science Letters 193 (3-4), pp. 333-345. DoI: 10. 1016/s0012-821x(01)00499-x.

Chanceaux, L. and T. Menand (2016). "The effects of solidification on sill propagation dynamics and morphology". Earth and Planetary Science Letters 442, pp. 39-50. Dor: 10.1016/j .epsl .2016.02.044.

Corry, C. E. (1988). "Laccoliths Mechanics of emplacement and growth". Geological Society of America Special Papers. Geological Society of America, pp. 1-114. DoI: $10.1130 /$ spe220-p1. Special Paper 220.

Currier, R. M. and B. D. Marsh (2015). "Mapping real time growth of experimental laccoliths: The effect of solidification on the mechanics of magmatic intrusion". Journal of Volcanology and Geothermal Research 302, pp. 211-224. Dor: 10.1016/ j . jvolgeores . 2015. 07.009.

d'Escatha, Y. and J. Mandel (1974). "Stabilité d'une galerie peu profonde en terrain meuble". Industrie Minerale, pp. $45-53$.

Delaney, P. T. and D. D. Pollard (1981). "Deformation of host rocks and flow of magma during growth of minette dikes and breccia-bearing intrusions near Ship Rock, New Mexico". Professional Paper. Dor: 10. 3133/pp1202.

DiGMapGB-50 (2013). SHAPE geospatial data. http://digimap.edina.ac.uk. EDINA Geology Digimap Service. [Scale 1:50000; Tiles: sc080w, sc058e_112w; Updated: 1 October 2013, BGS].

DiGMapGB-625 (2010). SHAPE geospatial data. http://digimap.edina.ac.uk. EDINA Geology Digimap Service. [Scale 1:625000; Tiles: GB; Updated: 17 August 2010, BGS].

Dingwell, D. B. (2006). "Transport Properties of Magmas: Diffusion and Rheology". Elements 2 (5), pp. 281-286. DoI: 10.2113/gselements.2.5.281.

Fossen, H. and A. Rotevatn (2016). "Fault linkage and relay structures in extensional settings-A review". Earth-Science Reviews 154, pp. 14-28. Dor: 10.1016/ j. earscirev.2015.11.014.

Fowler, S. J., W. A. Bohrson, and F. J. Spera (2004). "Magmatic Evolution of the Skye Igneous Centre, Western Scotland: Modelling of Assimilation, Recharge and Fractional Crystallization". Journal of Petrology 45 (12), pp. 2481-2505. DOI: 10. 1093 / petrology/egh074.

Galland, O., S. Burchardt, E. Hallot, R. Mourgues, and C. Bulois (2014). "Dynamics of dikes versus cone 
sheets in volcanic systems". Journal of Geophysical Research: Solid Earth 119 (8), pp. 6178-6192. Dor: 10.1002/2014jb011059.

Galland, O., J. B. Spacapan, O. Rabbel, K. Mair, F. G. Soto, T. Eiken, M. Schiuma, and H. A. Leanza (2019). "Structure, emplacement mechanism and magmaflow significance of igneous fingers - Implications for sill emplacement in sedimentary basins". Journal of Structural Geology 124, pp. 120-135. DoI: 10.1016/j. jsg.2019.04.013.

Gibb, F. G. F. and S. A. Gibson (1989). "The Little Minch Sill Complex". Scottish Journal of Geology 25 (3), pp. 367-370. DoI: 10.1144/sjg25030367.

Gill, S. P. A. and R. J. Walker (2020). "The Roles of Elastic Properties, Magmatic Pressure, and Tectonic Stress in Saucer-Shaped Sill Growth". Journal of Geophysical Research: Solid Earth 125 (4). Dor: 10.1029/ 2019jb019041.

Greenspan, M. (1944). "Effect of a small hole on the stresses in a uniformly loaded plate". Quarterly of Applied Mathematics 2 (1), pp. 60-71. Dor: 10.1090/ qam/10101.

Gudmundsson, A. (2011). "Rock Fractures in Geological Processes". Dor: 10.1017/cbo9780511975684.

Guldstrand, F., S. Burchardt, E. Hallot, and O. Galland (2017). "Dynamics of Surface Deformation Induced by Dikes and Cone Sheets in a Cohesive Coulomb Brittle Crust". Journal of Geophysical Research: Solid Earth 122 (10), pp. 8511-8524. DOI: 10.1002 / $2017 j b 014346$.

Hansen, D. M. and J. Cartwright (2006). "Saucershaped sill with lobate morphology revealed by 3D seismic data: implications for resolving a shallowlevel sill emplacement mechanism". Journal of the Geological Society 163 (3), pp. 509-523. Dor: 10.1144/ $0016-764905-073$.

Haug, Ø. T., O. Galland, P. Souloumiac, A. Souche, F. Guldstrand, T. Schmiedel, and B. Maillot (2018). "Shear Versus Tensile Failure Mechanisms Induced by Sill Intrusions: Implications for Emplacement of Conical and Saucer-Shaped Intrusions". Journal of Geophysical Research: Solid Earth 123 (5), pp. 34303449. DOI: $10.1002 / 2017$ jb015196.

Haug, Ø. T., O. Galland, P. Souloumiac, A. Souche, F. Guldstrand, and T. Schmiedel (2017). "Inelastic damage as a mechanical precursor for the emplacement of saucer-shaped intrusions". Geology 45 (12), pp. 1099 1102. DoI: $10.1130 / \mathrm{g} 39361.1$.

Healy, D., R. Rizzo, M. Duffy, N. Farrell, M. Hole, and D. Muirhead (2018). "Field evidence for the lateral emplacement of igneous dykes: Implications for 3D mechanical models and the plumbing beneath fissure eruptions". Volcanica 1 (2), pp. 85-105. Dor: 10.30909/vol.01.02.85105.

Hess, K.-U. and D. B. Dingwell (1996). "Viscosities of hydrous leucogranitic melts: A non-Arrhenian model". American Mineralogist: Journal of Earth and Planetary Materials 81 (9-10), pp. 1297-1300.
Hunt, C. B., P. Averitt, and R. L. Miller (1953). Geology and geography of the Henry Mountains region, Utah. DOI: 10.3133/pp228. Professional Paper 228.

Hutton, D. H. W. (2009). "Insights into magmatism in volcanic margins: bridge structures and a new mechanism of basic sill emplacement - Theron Mountains, Antarctica". Petroleum Geoscience 15 (3), pp. 269278. DoI: $10.1144 / 1354-079309-841$.

Inglis, C. E. (1913). "Stresses in a plate due to the presence of cracks and sharp corners". Transactions of the Institute of Naval Architects 55, pp. 219-241.

Jaeger, J. C., N. G. Cook, and R. Zimmerman (2007). Fundamentals of rock mechanics. Oxford: Blackwell Publishing Ltd.

Johnson, A. M. and D. D. Pollard (1973). "Mechanics of growth of some laccolithic intrusions in the Henry mountains, Utah, I: Field observations, Gilbert's model, physical properties and flow of the magma". Tectonophysics 18 (3-4), pp. 261-309. DoI: 10.1016/0040-1951(73)90050-4.

Kavanagh, J. and R. J. Sparks (2011). "Insights of dyke emplacement mechanics from detailed 3D dyke thickness datasets". Journal of the Geological Society 168 (4), pp. 965-978. Dor: 10.1144/0016-76492010137.

Kjøll, H. J., O. Galland, L. Labrousse, and T. B. Andersen (2019). "Emplacement mechanisms of a dyke swarm across the brittle-ductile transition and the geodynamic implications for magma-rich margins". Earth and Planetary Science Letters 518, pp. 223-235. DoI: 10.1016/j.eps1.2019.04.016.

Kokelaar, B. P. (1982). "Fluidization of wet sediments during the emplacement and cooling of various igneous bodies". Journal of the Geological Society 139 (1), pp. 21-33. Dor: 10.1144/gsjgs.139.1.0021.

Lamé, G. (1818). Examen des différentes méthodes employées pour résoudre les problèmes de géométrie. Mme Ve Courcier, rue du Jardinet-Saint-André-des-Arcs.

Lawn, B. R. (1975). Fracture of brittle solids. Cambridge solid state science series. Cambridge: Cambridge university press.

Lister, J. R. (1990). "Buoyancy-driven fluid fracture: the effects of material toughness and of low-viscosity precursors". Journal of Fluid Mechanics 210, pp. 263280. DOI: $10.1017 / \mathrm{s} 0022112090001288$.

Long, J. J. and J. Imber (2011). "Geological controls on fault relay zone scaling". Journal of Structural Geology 33 (12), pp. 1790-1800. Dor: 10.1016/j . jsg. 2011. 09.011.

Magee, C., B. O'Driscoll, M. Petronis, and C. Stevenson (2016). "Three-dimensional magma flow dynamics within subvolcanic sheet intrusions". Geosphere 12 (3), pp. 842-866. Dor: 10.1130/ges01270.1.

Magee, C., C. T. E. Stevenson, S. K. Ebmeier, D. Keir, J. O. S. Hammond, J. H. Gottsmann, K. A. Whaler, N. J. Schofield, C. A.-L. Jackson, M. S. Petronis, and et al. (2018). "Magma Plumbing Systems: A Geophysi- 
cal Perspective". Journal of Petrology 59 (6), pp. 12171251. Dor: $10.1093 /$ petrology/egy064.

Martin, S. A., J. L. Kavanagh, A. J. Biggin, and J. E. P. Utley (2019). "The Origin and Evolution of Magnetic Fabrics in Mafic Sills". Frontiers in Earth Science 7. DOI: 10.3389/feart.2019.00064.

Martínez-Poza, A., E. Druguet, L. Castaño, and J. Carreras (2014). "Dyke intrusion into a pre-existing joint network: The Aiguablava lamprophyre dyke swarm (Catalan Coastal Ranges)". Tectonophysics 630, pp. 75-90. Dor: 10.1016/j. tecto.2014.05.015.

Mathieu, L., B. van Wyk de Vries, E. P. Holohan, and V. R. Troll (2008). "Dykes, cups, saucers and sills: Analogue experiments on magma intrusion into brittle rocks". Earth and Planetary Science Letters 271 (14), pp. 1-13. Dor: 10.1016/j.eps1.2008.02.020.

Mattsson, T., S. Burchardt, B. S. G. Almqvist, and E. Ronchin (2018). "Syn-Emplacement Fracturing in the Sandfell Laccolith, Eastern Iceland-Implications for Rhyolite Intrusion Growth and Volcanic Hazards". Frontiers in Earth Science 6. Dor: $10.3389 /$ feart. 2018.00005.

Merle, O. and F. Donnadieu (2000). "Indentation of volcanic edifices by the ascending magma". Geological Society, London, Special Publications 174 (1), pp. 4353. Dor: 10.1144/gsl.sp.1999.174.01.03.

Nádai, A. (1950). Theory of flow and fracture of solids. Vol. 1. New York: McGraw-Hill. [2nd edition].

Nicholson, R. and D. D. Pollard (1985). "Dilation and linkage of echelon cracks". Journal of Structural Geology 7 (5), pp. 583-590. Dor: 10.1016/0191-8141(85) 90030-6.

Obert, L. and W. I. Duvall (1967). Rock mechanics and the design of structures in rock. Vol. 650. Wiley New York.

Pollard, D. D. (1973). "Derivation and evaluation of a mechanical model for sheet intrusions". Tectonophysics 19 (3), pp. 233-269. Dor: 10 . 1016/00401951(73) 90021-8.

Pollard, D. D., O. H. Muller, and D. R. Dockstader (1975). "The Form and Growth of Fingered Sheet Intrusions". Geological Society of America Bulletin 86 (3), p. 351. Dor: $10.1130 / 0016-7606$ (1975) 86<351: tfagof $>2.0$. co; 2 .

Pollard, D. D., P. Segall, and P. T. Delaney (1982). "Formation and interpretation of dilatant echelon cracks". Geological Society of America Bulletin 93 (12), p. 1291. DoI: 10 . $1130 / 0016-7606(1982) 93<1291$ : faiode $>2.0$. co; 2 .

Poppe, S., O. Galland, N. J. Winter, S. Goderis, P. Claeys, V. Debaille, P. Boulvais, and M. Kervyn (2020). "Structural and Geochemical Interactions Between Magma and Sedimentary Host Rock: The Hovedøya Case, Oslo Rift, Norway". Geochemistry, Geophysics, Geosystems 21 (3). DOI: 10.1029/2019gc008685.

Poppe, S., E. P. Holohan, O. Galland, N. Buls, G. Van Gompel, B. Keelson, P.-Y. Tournigand, J. Brancart, D. Hollis, A. Nila, and et al. (2019). "An Inside Perspec- tive on Magma Intrusion: Quantifying 3D Displacement and Strain in Laboratory Experiments by Dynamic X-Ray Computed Tomography". Frontiers in Earth Science 7. Dor: 10.3389/feart.2019.00062.

Roberts, A. M. and R. E. Holdsworth (1999). "Linking onshore and offshore structures: Mesozoic extension in the Scottish Highlands". Journal of the Geological Society 156 (6), pp. 1061-1064. Dor: 10.1144/gsjgs . 156.6.1061.

Robertson, E. C. (1988). Thermal properties of rocks. Tech. rep. Open-File Report 95-114.

Rubin, A. M. (1993). "Tensile fracture of rock at high confining pressure: Implications for dike propagation". Journal of Geophysical Research 98 (B9), p. 15919. DOI: 10.1029/93jb01391.

- (1995). "Propagation of Magma-Filled Cracks". Annual Review of Earth and Planetary Sciences 23 (1), pp. 287-336. Dor: 10.1146/annurev . ea .23.050195. 001443.

Saffman, P. G. and G. Taylor F. R. S. (1958). "The penetration of a fluid into a porous medium or Hele-Shaw cell containing a more viscous liquid". Proceedings of the Royal Society of London. Series A. Mathematical and Physical Sciences 245 (1242), pp. 312-329. DoI: 10.1098/rspa.1958.0085.

Saunders, A. D., J. G. Fitton, A. C. Kerr, M. J. Norry, R. W. Kent, J. J. Mahoney, and M. F. Coffin (1997). "The north Atlantic igneous province". Large igneous provinces: Continental, Oceanic, and Planetary Flood Volcanism. Ed. by J. J. Mahoney and M. F. Coffin. Vol. 100. AGU American Geophysical Union, pp. 4594.

Schmiedel, T., O. Galland, and C. Breitkreuz (2017). "Dynamics of Sill and Laccolith Emplacement in the Brittle Crust: Role of Host Rock Strength and Deformation Mode". Journal of Geophysical Research: Solid Earth 122 (11), pp. 8860-8871. Dor: 10.1002/ $2017 j b 014468$.

Schmiedel, T., O. Galland, Ø. Haug, G. Dumazer, and C. Breitkreuz (2019). "Coulomb failure of Earth's brittle crust controls growth, emplacement and shapes of igneous sills, saucer-shaped sills and laccoliths". Earth and Planetary Science Letters 510, pp. 161-172. Dor: 10.1016/j . epsl.2019.01.011.

Schofield, N. J., I. Alsop, J. Warren, J. R. Underhill, R. Lehné, W. Beer, and V. Lukas (2014). "Mobilizing salt: Magma-salt interactions". Geology 42 (7), pp. 599-602. DoI: 10.1130/g35406.1.

Schofield, N. J., D. J. Brown, C. Magee, and C. T. Stevenson (2012). "Sill morphology and comparison of brittle and non-brittle emplacement mechanisms". Journal of the Geological Society 169 (2), pp. 127-141. Dor: 10.1144/0016-76492011-078.

Schofield, N. J., D. A. Jerram, S. Holford, S. Archer, N. Mark, A. Hartley, J. Howell, D. Muirhead, P. Green, D. Hutton, and C. Stevenson (2016). "Sills in Sedimentary Basins and Petroleum Systems". Physical Geology of Shallow Magmatic Systems. Ed. by B. C. and 
R. S. Springer International Publishing, pp. 273-294. ISBN: 978-3-319-14083-4. DOI: 10.1007/11157_2015_ 17.

Schofield, N. J., C. Stevenson, and T. Reston (2010). "Magma fingers and host rock fluidization in the emplacement of sills". Geology 38 (1), pp. 63-66. Dor: $10.1130 / g 30142.1$.

Shaw, H. R. (1969). "Rheology of Basalt in the Melting Range". Journal of Petrology 10 (3), pp. 510-535. Dor: $10.1093 /$ petrology/10.3.510.

Souche, A., O. Galland, Ø. T. Haug, and M. Dabrowski (2019). "Impact of host rock heterogeneity on failure around pressurized conduits: Implications for fingershaped magmatic intrusions". Tectonophysics 765, pp. 52-63. Dor: 10.1016/j . tecto. 2019.05.016.

Spacapan, J. B., O. Galland, H. A. Leanza, and S. Planke (2017). "Igneous sill and finger emplacement mechanism in shale-dominated formations: a field study at Cuesta del Chihuido, Neuquén Basin, Argentina”. Journal of the Geological Society 174 (3), pp. 422-433. DoI: $10.1144 /$ jgs2016-056.

Stephens, T. L., R. J. Walker, D. Healy, A. Bubeck, and R. W. England (2018). "Mechanical models to estimate the paleostress state from igneous intrusions". Solid Earth 9 (4), pp. 847-858. Dor: $10.5194 / \mathrm{se}-9$ 847-2018.

Tentler, T. and V. Acocella (2010). "How does the initial configuration of oceanic ridge segments affect their interaction? Insights from analogue models". Journal of Geophysical Research 115 (B1). Dor: 10.1029/ 2008 jb006269.

Vachon, R. and C. F. Hieronymus (2017). "Effect of hostrock rheology on dyke shape, thickness and magma overpressure". Geophysical Journal International 208 (3), pp. 1414-1429. Dor: 10.1093/gji/ggw448.
Wadell, H. (1935). "Volume, Shape, and Roundness of Quartz Particles". The Journal of Geology 43 (3), pp. 250-280. DOI: 10.1086/624298.

Walker, R. J. and S. P. A. Gill (2020). "Tectonic stress controls saucer-shaped sill geometry and emplacement mechanism". Geology 48 (9), pp. 898-902. Dor: $10.1130 / g 47604.1$.

Walker, R. J., D. Healy, T. M. Kawanzaruwa, K. A. Wright, R. W. England, K. J. W. McCaffrey, A. A. Bubeck, T. L. Stephens, N. J. C. Farrell, and T. G. Blenkinsop (2017). "Igneous sills as a record of horizontal shortening: The San Rafael subvolcanic field, Utah". Geological Society of America Bulletin, B31671.1. DoI: 10.1130/b31671.1.

Walker, R. J., T. L. Stephens, C. Greenfield, S. P. A. Gill, D. Healy, and S. Poppe (2021). "Segment tip geometry of sheet intrusions, I: Theory and numerical models for the role of tip shape in controlling propagation pathways". Volcanica 4 (2), pp. 189-201. Dor: 10.30909/vol.04.02.189201.

Wilson, P. I. R., K. J. W. McCaffrey, R. W. Wilson, I. Jarvis, and R. E. Holdsworth (2016). "Deformation structures associated with the Trachyte Mesa intrusion, Henry Mountains, Utah: Implications for sill and laccolith emplacement mechanisms". Journal of Structural Geology 87, pp. 30-46. Dor: $10.1016 / \mathrm{j}$. jsg.2016.04.001.

Wyrick, D. Y., A. P. Morris, M. K. Todt, and M. J. Watson-Morris (2015). "Physical analogue modelling of Martian dyke-induced deformation". Volcanism and Tectonism Across the Inner Solar System. Ed. by T. Platz, M. Massironi, P. K. Byrne, and H. Hiesinger. Vol. 401. Geological Society of London, pp. 395-403. DOI: $10.1144 / \mathrm{sp} 401.15$. 